\title{
ROMPIMENTO DE BARRAGENS EM MARIANA E BRUMADINHO - MG: Desastres como meio de acumulação por despossessão
}

\author{
DAM BREAKS IN MARIANA AND BRUMADINHO - MG: \\ Disasters as a means of accumulation by dispossession
}

DAMMBRÜCHE IN MARIANA UND BRUMADINHO - MG:

Katastrophen als Mittel zur Akkumulation durch Enteignung

\begin{abstract}
Resumo:
A ruptura de duas barragens em Minas Gerais - em Mariana (2015) e em Brumadinho (2019) custou centenas de vidas e destruiu a maior parte das bacias do Rio Doce e do Rio Paraopeba. Esses eventos são o auge dos desastres, que começaram com o licenciamento ambiental e continuaram com uma ineficiente gestão de reparação de danos, causando ainda mais sofrimento social. Após os desastres, as instituições públicas, além de não fortalecerem o marco regulatório, aceleraram sua flexibilização. Como resultado, as empresas de mineração puderam introduzir a cultura do neocoronelismo nos sistemas de governança, ou seja, não somente fortaleceram seus interesses frente às demandas das vítimas, como também aumentaram o controle territorial das áreas afetadas pelos desastres por meio de "grilagem oculta de terras" (hidden landgrabbing).
\end{abstract}

Palavras-chave: Barragem de rejeito; Desastre; Acumulação por despossessão; Mineração; Licenciamento ambiental; Reparação de danos.

\begin{abstract}
:
The rupture of two dams in Mariana (MG), 2015, and Brumadinho (MG), 2019, cost hundreds of lives and destroyed most of the Rio Doce and Paraopeba basins. These events are the climax of the disasters that began with environmental licensing and continued with the inefficient management of damage repair, causing even more social suffering. After the disasters, public institutions did not strengthen the regulatory framework but accelerated its flexibilization. As a result, mining companies are able to introduce the culture of neocoronelism into governance systems. In this way, companies have not only strengthened their interests in the face of victims' demands, but also the territorial control in areas affected by disasters through "hidden land grabbing".
\end{abstract}

Keywords: Tailings dam; disaster, accumulation by dispossession; mining; environmental licensing; reparation of damage.

\section{Zusammenfassung:}

Der Bruch von zwei Dämmen in Mariana (MG), 2015, und Brumadinho (MG), 2019, kostete Hunderte von Menschenleben und zerstörte große Teile der Becken der beiden Flüsse Rio Doce und Paraopeba. Diese stellen die Höhepunkte von Desastern dar, die bereits während des Umweltverträglichkeitsprüfungsverfahrens begannen und sich auch danach über das ineffiziente Management der Schadenserhebung hinziehen und so noch mehr soziales Leid verursachen. Nach den Katastrophen haben die öffentlichen Institutionen die regulatorischen Rahmenbedingungen nicht gestärkt, sondern sogar deren Flexibilisierung beschleunigt. Dadurch sind die Bergbauunternehmen in der Lage, die Kultur des "Neokoronelismus" in die GovernanceSysteme einzubringen. Auf diese Weise haben die Unternehmen nicht nur ihre Interessen gegenüber der Forderungen der Opfer gestärkt, sondern auch die Gebietskontrolle in den betroffenen Gebieten durch "hidden landgrabbing" ausgeweitet.

Schlüsselwörter: Abraumhalde; Desaster, Akkumulation durch Enteignung; Bergbau; Umweltverträglichkeitsprüfung; Schadensbeseitigung.

\section{Introdução}


"Não foi um acidente - foi um crime", protestam cidadãos indignados após o colapso das duas barragens de rejeitos - a do Fundão, de propriedade da empresa Samarco Mineração S.A. (uma Joint Venture entre a Vale S.A. e a multinacional australiana BHP Billiton), em Mariana/MG, em 2015, e a do Córrego do Feijão, administrada pela Vale S.A., em Brumadinho/MG, em 2019. Esses dois eventos figuram entre os maiores desastres ambientais do mundo no setor de mineração. No caso do colapso da barragem do Fundão, 60 milhões de metros cúbicos de lama tóxica foram despejados em um percurso de 663 quilômetros dos rios Gualaxo do Norte, Carmo e Doce. A avalanche causou 19 mortes, levou a casa de cerca de 1200 famílias e atingiu 35 municípios, sendo que os povoados Bento Rodrigues e Paracatu foram completamente destruídos. Como mostram vários trabalhos, o evento não foi resultado de uma catástrofe natural, mas sim de uma negligência criminosa. Negligência não apenas das empresas envolvidas, mas também dos órgãos públicos responsáveis pelo licenciamento e pela fiscalização das barragens (ZHOURI et al, 2016, 2017; LACAS, PORTO, PINHEIRO, 2017; MILANES, MAGNO, GIFFONI, 2019, entre outros). De fato, o desastre já havia começado na fase do planejamento e ainda não se concluiu; até a data da elaboração deste texto, ninguém foi preso e os problemas das vítimas estão longe de serem resolvidos.

No caso da ruptura da barragem do Córrego do Feijão, segundo as últimas informações, incluindo 14 pessoas desaparecidas, 270 pessoas perderam a vida (ROCHA, 2019) e a contaminação pela lama com substâncias tóxicas se estende por mais de $300 \mathrm{~km}$ no Rio Paraopeba (ARAGAKI, 2019).

Ambos os desastres sociotécnicos (ZHOURI et al, 2016) aconteceram em um raio de menos de $45 \mathrm{~km}$, evidenciando, assim, o risco eminente configurado por dezenas de empreendimentos de mineradoras no Quadrilátero Ferrífero na Região Metropolitana de Belo Horizonte, sobre os quais já constavam vários antecedentes. Entre os mais graves, destacam-se, segundo Lacas, Porto, Pinheiro (2017), os rompimentos de barragens em Itabirito, em 1986 (seis mortos) e em 2014 (3 mortos); em Nova Lima, em 2001 (5 mortos) e em Congonhas, em 2008 (40 famílias desalojadas)(Mapa 1). 
Mapa 1: "Terrorismo de barragens"

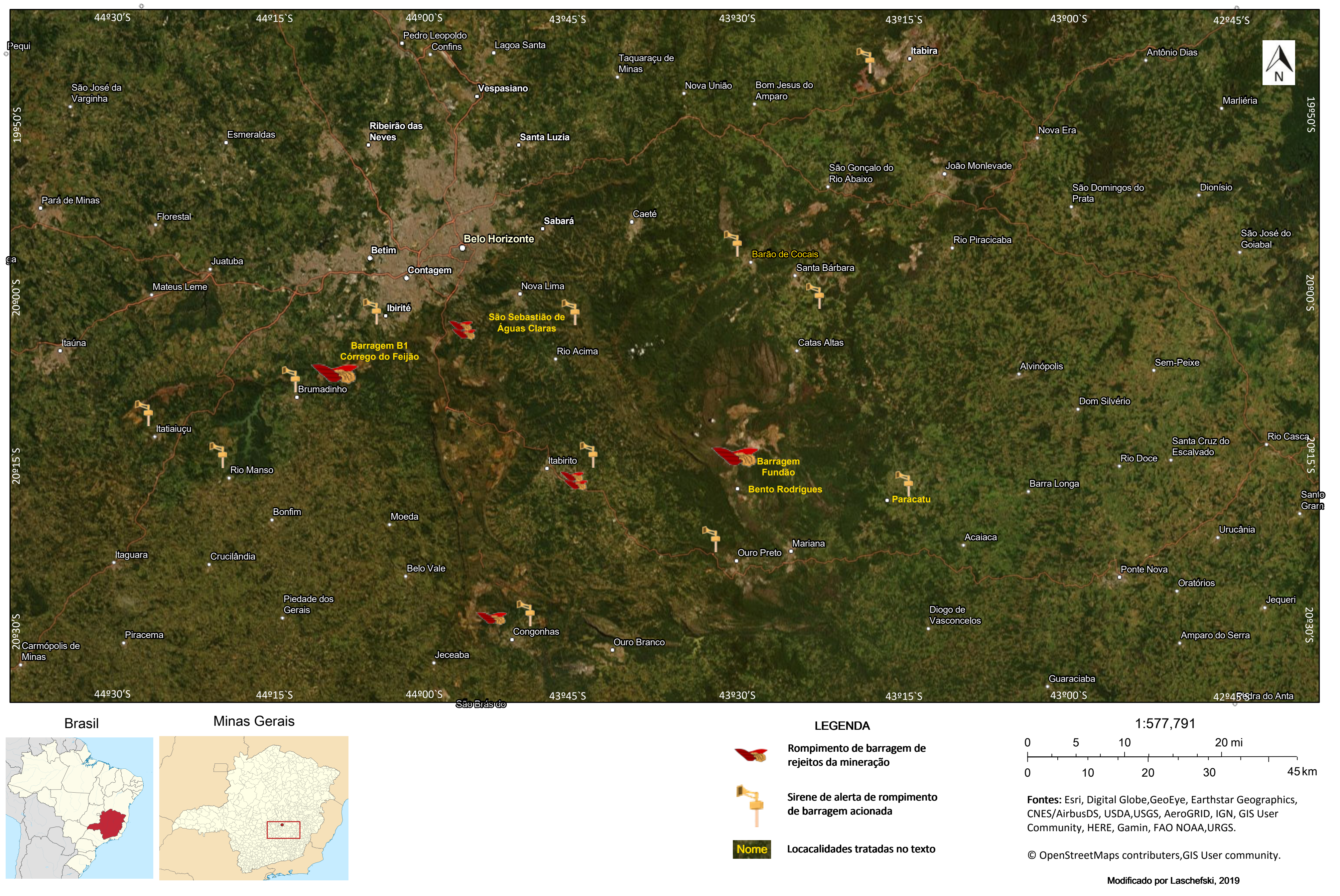


A frequência de tais incidentes indica que as "negligências" amplamente discutidas em relação aos casos de Mariana e Brumadinho têm, na verdade, uma longa história, que aponta o caráter sistêmico da ineficiência dos processos de tomada de decisão em torno das licenças ambientais e da fiscalização. Observa-se essa deficiência também na gestão da reparação dos danos, o que causa ainda mais sofrimento social para as vítimas, enquanto a recuperação econômica das empresas responsáveis por tais crimes socioambientais acontece rapidamente. No período entre os dois desastres (2015 a 2018), a Vale triplicou seus lucros e tudo indica que mesmo o desastre do

Brumadinho não afetará a imagem da empresa de forma a causar maiores prejuízos

(MANFREDINI, 2019).

Perante a riqueza das empresas, perguntamo-nos: por que os processos de avaliação dos danos, assim como os de reparação e indenização das vítimas, demoram tanto tempo e são tão cruéis? Por que os sistemas de governança estabelecidos não conseguem se afirmar contra essas empresas multinacionais para encontrar soluções pragmáticas para restaurar as condições de vida das vítimas? Por que os moradores atingidos são confrontados com inúmeras reuniões improdutivas para negociar valores monetários ridículos diante dos lucros corporativos? Escondem-se por trás dessas questões novas estratégias de acumulação por despossessão (HARVEY, 2004) que permitem a instrumentalização dos desastres para a geração de lucro e a instalação de novas formas de apropriação territorial fora das "leis severas do processo econômico" (LUXEMBURG, 1913)?

Neste texto, não temos a intenção de aprofundar as reflexões sobre essas abordagens teóricas. Contudo, a nosso ver, parece haver um novo modo de produção não-capitalista centrado no controle territorial que, por meio de uma articulação intensa com órgãos públicos, entidades da sociedade civil e o ministério público, sob o guarda-chuva da 'boa governança', busca soluções extrajudiciais, como preveem as abordagens desenvolvidas no âmbito das políticas do Banco Mundial (LASCHEFSKI, 2014). Portanto, partimos do pressuposto de que não é o deslocamento do capital em tempos de acumulação excessiva que promove a espoliação, como disse Harvey (2004), mas as próprias catástrofes estão sendo configuradas como parte do ambiente não-capitalista de acumulação após o colapso localizado do capital.

Foto 1: Escritos nas paredes das ruínas em Bento Rodrigues, MG 

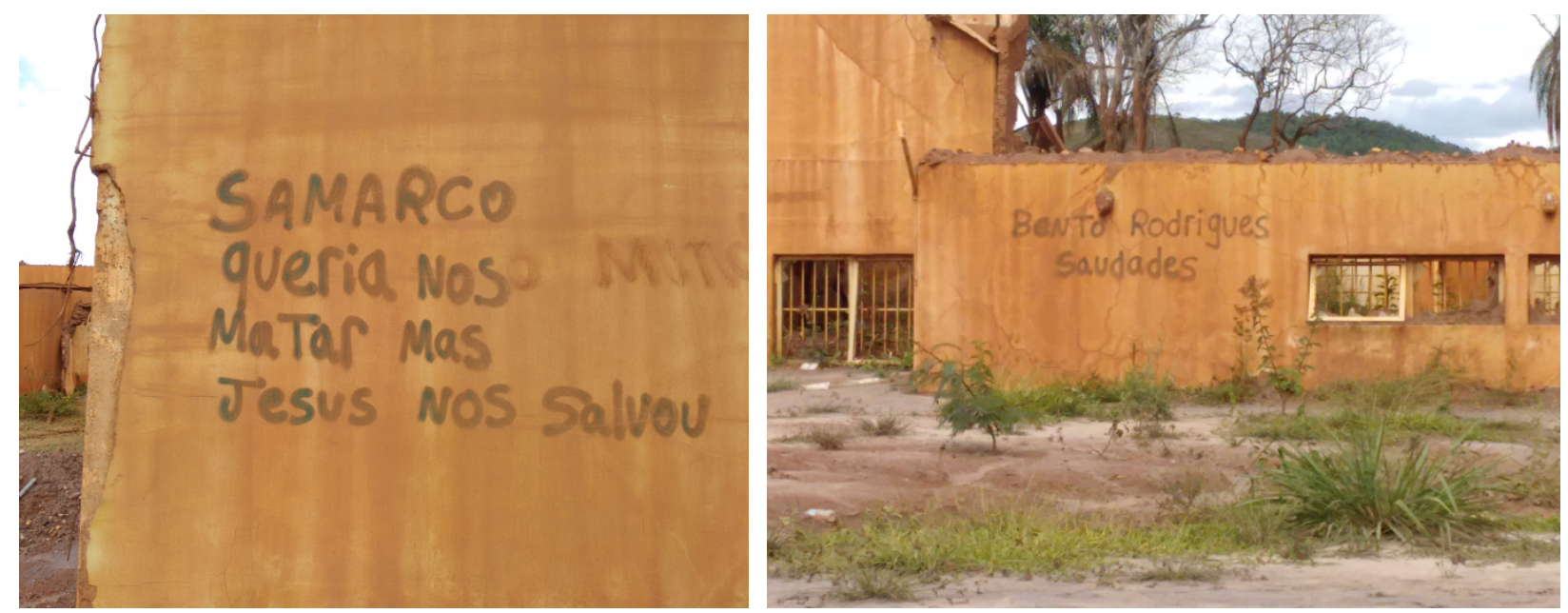

Foto: Laschefski, 2016.

Nesse contexto, as mineradoras são capazes de influenciar as relações de poder nas estruturas de governança, de forma a se beneficiarem. Focalizamos neste trabalho duas estratégiaschave: 1) a instalação de canais de influência no Sistema Estadual de Meio Ambiente e Recursos Hídricos (SISEMA) do Estado de Minas Gerais e 2) a gestão dos desastres ocorridos em Mariana e Brumadinho.

Este trabalho baseia-se em dados empíricos obtidos em atividades de pesquisa e extensão realizadas desde 2015, que envolvem: a) métodos de observação participante em reuniões e audiências dos órgãos ambientais, do Ministério Público e da Assembleia Legislativa de Minas Gerais; b) assessoria prestada às vítimas e às assistências técnicas, entidades da sociedade civil e movimentos sociais; c) o acompanhamento da reestruturação do sistema ambiental e do processo de licenciamento em Minas Gerais e os seus reflexos em nível federal.

\section{A adequação do sistema ambiental em Minas Gerais aos interesses das mineradoras}

Nas últimas duas décadas, investigamos como as regulamentações ambientais e a participação pública no campo ambiental têm sido gradualmente corroídas em Minas Gerais (ZHOURI, LASCHEFSKI, PAIVA, 2005; ZHOURI, 2008; LASCHEFSKI, 2014). Surpreendentemente, as expectativas de que esse processo se invertesse depois das catástrofes, como a sociedade civil já vinha exigindo há algum tempo, não foram cumpridas. Ao contrário, as instituições decidiram não apertar a legislação ambiental, mas acelerar ainda mais o processo de flexibilização. Isso ocorreu porque as mineradoras conseguiram instalar uma rede de interferência que inclui não só a Câmara dos Deputados, mas também o governo, o Conselho de Política Ambiental (COPAM) e o Ministério Público, além de instituições da sociedade civil, movimentos 
sociais e, ainda, universidades e suas instituições de fomento. Foram criados canais de influência institucionalizados, que permaneceram intactos mesmo após a eleição, em 2018, de um governo que se dizia comprometido com a renovação da política no Estado de Minas Gerais. A convergência sobre essa questão entre o governo anterior - do Partido dos Trabalhadores (PT), considerado de esquerda - e o atual governo - do Partido Novo, considerado de direita (que apoiou a eleição do presidente Bolsonaro) - ilustra muito bem o "consenso das commodities" (SWAMPA, 2013), que se reflete na tendência de reprimarização da economia em toda a América Latina. Além das visões ideológicas de desenvolvimento compartilhadas por ambos os grupos, que discutiremos a seguir, a causa desse fenômeno pode ser encontrada em razões muito práticas: em 2014, 78,4\% dos deputados estaduais e federais de Minas Gerais, independentemente de sua orientação política, tiveram sua campanha eleitoral financiada por mineradoras (MATEUS, 2019). Dessa forma, as mineradoras garantem as maiorias necessárias nas representações políticas para mudanças na regulação ambiental a seu favor. Exemplo disso são as inovações no sistema ambiental de Minas Gerais, introduzidas pelo Projeto de Lei - PL 2.946/15, aprovada em 25 de novembro de 2015 apenas 20 dias após o colapso da barragem localizada em Mariana - e sua adoção como Lei $n^{\circ}$ 21.972, em 21 de janeiro de 2016. O ponto mais importante dessa Lei é a criação da Superintendência de Projetos Prioritários (SUPPRI), responsável por acelerar o processo do licenciamento. A essa Superintendência foi atribuída a competência de retirar e analisar processos que estejam tramitando no COPAM, mas que sejam considerados importantes pelo Conselho Estadual de Desenvolvimento Econômico e Social (para projetos privados) ou pela Secretaria de Estado de Meio Ambiente e Desenvolvimento Sustentável (para projetos públicos), e devolvê-los com uma "recomendação de voto" para os conselheiros (Art. 24). Discutiremos as consequências dessas mudanças na Seção 4, que trata do desastre em torno da ruptura da barragem Córrego do Feijão em Brumadinho. Antes, porém, vamos analisar a gestão do desastre após o rompimento da barragem de Mariana.

Em ambos os casos de ruptura de barragens, cresceu, no primeiro momento, a preocupação com o futuro da mineração em geral nas comunidades afetadas. Mas, assim que tomou fôlego a discussão sobre a Compensação Financeira pela Exploração de Recursos Minerais (CFEM) contraprestação estabelecida pela constituição de 1988 para que os municípios investissem em alternativas econômicas para amenizar os efeitos do fechamento das minas depois do esgotamento do minério (ALMG, 2019) -, observou-se o resgate do discurso sobre a "vocação mineral" do Estado de Minas Gerais. São, principalmente, os prefeitos de Brumadinho e Mariana que, frequentemente, chamam a atenção para a importância da atividade minerária como fonte de arrecadação, geração de empregos e manutenção dos serviços públicos (G1 Minas, 2019c), fenômeno, às vezes, denominado minero-dependência (PALHA, 2019). Observa-se uma certa 
"monoculturação da mente" (SHIVA, 1993), que se reflete no papel central das atividades de mineração na fundamentação ideológica de estratégias "inquestionáveis" de (neo)desenvolvimento nas instâncias decisórias do Estado e dos municípios. A FIEMG (2019) estimou que a perda de empregos devido à descontinuidade parcial da atividade de extração minerária pode chegar à marca de 1.480 .445 , se considerados todos os setores vinculados à mineração.

Apesar da relevância da CFEM para a administração dos municípios, tais pronunciamentos negligenciam o fato de que a mineração configura uma atividade com poucas décadas de duração e que a maioria da população daqueles municípios não vive dela. Como mostrado recentemente em um estudo sobre a produção do espaço em Brumadinho, setores econômicos relevantes, como agricultura familiar, produção artesanal de doces, cachaça e queijo e o turismo rural, raramente são o centro da atenção nas políticas públicas municipais (PALHA, 2019). Também é fato que, apesar do alto Índice de Desenvolvimento Humano (IDH) em municípios como Nova Lima - GINI alto, de 0,6914 em 2010 - e Brumadinho - GINI médio, de 0,5720 em 2010 (MOTA, BARCELOS, 2018)1 -, a mineração configura uma atividade de pouca articulação com os demais setores da economia e não necessariamente contribui para a redução da desigualdade social e a erradicação da pobreza.

Interessante destacar, nesse contexto, um trecho do relatório da CPI de Brumadinho e outras barragens:

[...] de acordo com a Agência Nacional de Mineração (ANM), a arrecadação da CFEM referente à produção de ferro somou R\$ 2,1 bilhões em 2018, o que equivale a menos de um dólar por tonelada extraída. Considerando que a cotação atual do minério de ferro gira em torno de US\$100/tonelada, trata-se de uma verdadeira espoliação do patrimônio nacional! (SENADO FEDERAL, 2019, p. $321)$.

A negligência e os crimes que marcam o início dos desastres em Mariana e Brumadinho apontam, além da falência das instituições públicas, o imperialismo das empresas multinacionais de mineração, que atendem, principalmente, aos mercados de países do centro ou daqueles que pretendem dominar a economia mundial, como a China. A diferença supracitada entre a CFEM e o preço do minério no mercado mundial pode ser explicada pela externalização dos custos causados por problemas sociais e danos ambientais no setor de mineração. De fato, o Brasil está, literalmente, entregando seu "espaço ambiental" a interesses externos. Dessa forma, podemos identificar na noção "vocação mineira" um elemento discursivo para justificar a reprimarização da economia brasileira. Isso reflete uma clara continuidade da lógica colonial - ou colonialidade (LANDER, 2005) - que permeia as políticas públicas desde os primeiros registros históricos de exploração

1 Cabe lembrar que estudos comparativos com base em indicadores quantitativos têm que ser lidos com cautela, uma vez que os municípios de Brumadinho e Nova Lima estão localizados na Região Metropolitana de Belo Horizonte e suas estruturas diversificadas atraem moradores de alta renda, que trabalham em Belo Horizonte, a capital e centro econômico do Estado. 
minerária, coincidindo precisamente com a ascensão de Mariana (Vila do Carmo), no século XVII, como a primeira vila de Minas Gerais (REIS, 2007).

\section{A gestão dos desastres em Mariana e Brumadinho}

\subsection{Boa governança e gestão do desastre depois do rompimento da barragem do Fundão, em 2015}

Provavelmente, foi a "vocação mineira" que - erroneamente, em nossa opinião - contribuiu para a implementação de um esquema de resolução negociada de conflitos como elemento central na definição da reparação dos danos causados pelos desastres. A estratégia foi consolidada com um projeto do Banco Mundial, em cooperação com o Ministério Público de Minas Gerais (MPMG), para encontrar soluções extrajudiciais no âmbito do conceito de "boa governança" em casos de conflitos em torno do licenciamento ambiental, uma vez que o judiciário brasileiro é quase inoperante. Essa abordagem acabou de ser testada no contexto de projetos de mineração (LASCHEFSKI, 2014). Logo após o rompimento da barragem em Mariana, o Grupo de Estudos em Temáticas Ambientais (GESTA, 2015) fez uma representação ao MPMG denunciando que a reparação dos danos às vítimas não se encaixava na lógica de uma negociação de interesses para resolver conflitos entre partes iguais. Segundo o GESTA, era necessário agir decisivamente, com base nos direitos garantidos pela Constituição, estabelecendo uma indenização justa para as vítimas do crime cometido pela ré - a Samarco. Assumir uma posição imparcial na mediação significa, de fato, cooperar com o crime. Nesse sentido, entendemos que o Ministério Público teria a obrigação constitucional de "tomar partido" a favor das vítimas, ou seja, na prática, registrar os danos e estabelecer reparações sem a intervenção das empresas causadoras do desastre. Vários trabalhos anteriores mostram que não foi isso que aconteceu. Em vez dessas propostas, os Ministérios Públicos Federal e Estaduais de Minas Gerais e Espírito Santo, juntamente com outros órgãos públicos, implementaram um sistema de governança em um processo turbulento que não será descrito em detalhes aqui, mas pode ser conhecido em Zhouri et al (2016; 2017) e Zucarelli (2018). A coordenadora do sistema de governança é a Fundação Renova, criada em 2016, por meio de um Termo de Transação e Ajustamento de Conduta (TTAC), comumente chamado de TAC Governança. A Renova emprega aproximadamente 7000 pessoas e mantém parcerias com mais de 25 universidades e 50 ONGs para conduzir 42 programas ambientais e sociais. Até maio de 2019, foram gastos 6,06 bilhões de reais, dos quais 1,61 bilhões foram destinados para indenizações de mais de 300000 pessoas por danos em relação à água, danos gerais e auxílios financeiros emergenciais (RENOVA, 2019a). Apesar desses números impressionantes, observamos, durante 
nossas pesquisas de campo, que a situação das vítimas de Bento Rodrigues e Paracatu diretamente prejudicadas está longe de ser resolvida. No quarto ano depois do rompimento, as pessoas que perderam suas casas vivem em moradias provisórias, sem perspectivas claras para o seu futuro. Os produtores rurais não conseguiram pagar os créditos bancários e perderam, assim, o direto de obter novos financiamentos do Programa Nacional de Fortalecimento da Agricultura Familiar (Pronaf) e muitas vítimas relataram, em depoimentos de maio de 2019, que ainda lutam para serem reconhecidas como atingidos. Mesmo sem entrar em detalhes, observamos três estratégias que geram grande insatisfação dos atingidos, apresentadas a seguir.

3.1.1 O cadastro e a exclusão de demandas das vítimas por meio da "objetivação" de danos

Imediatamente após o desastre no vale do Rio Doce, a Samarco encomendou, a várias empresas de consultoria, a elaboração de um cadastro das famílias prejudicadas. Essas empresas utilizaram questionários fechados (alguns compilados arbitrariamente) para elaborar uma espécie de inventário dos prejuízos materiais, a fim de poderem dar início ao processo de compensação. Após um teste com as famílias envolvidas, o GESTA constatou que a metodologia do cadastro era completamente inadequada para esse fim, uma vez que muitas das categorias utilizadas não estavam em linguagem compreensível para as vítimas ou não eram suficientemente precisas para capturar toda a dimensão das perdas (GESTA, 2016).

Nota-se, acima de tudo, que o método adotado busca a "objetivação" do registro de danos de forma padronizada, formulada a partir de uma perspectiva empresarial urbana e/ou agroindustrial, que não contempla as dimensões específicas dos, agricultores familiares, camponeses, pescadores artesanais, grupos tradicionais e étnicos. Essa lacuna limita o instrumento à aferição de dados majoritariamente patrimoniais e censitários, subsumidos em uma lógica que é estranha ao modo de vida da maioria da população. Assim, os instrumentos para o levantamento dos danos não englobam as redes de relações sociais territorializadas (trabalho, parentesco, vizinhança e apoio), formas de significação e uso do espaço e dos recursos, valores culturais, entre outros (GESTA, 2016).

Para superar esses problemas, o GESTA organizou, em fevereiro de 2017, uma oficina para apresentar um método para a elaboração de mapas comunitários, construídos pelas próprias vítimas, partindo dos desenhos das casas, terrenos, áreas de uso comunitário e relações de vizinhança/parentesco na comunidade. As perdas materiais relatadas pelos participantes também foram registradas durante os workshops. Os desenhos foram, posteriormente, georreferenciados e os registros computados, com o objetivo de construir uma base sólida de informações que fortalecesse a posição das vítimas na reivindicação de seus direitos. Também foram empregados métodos etnográficos para identificar "estratégias de vida" (BEBBINGTON, 1999), ou seja, os "modos de 
vida dos diferentes grupos e segmentos afetados, suas rotinas de subsistência, provisão e trabalho, sua territorialidade e as estruturas de relações sociais e condições ecológicas que sustentam tais rotinas" (GESTA, 2016). No entanto, a proposta foi só parcialmente acatada pelas equipes de assistência técnica.

Observamos, no pós-desastre, uma tendência de criminalização no que se refere a títulos de terra e atividades e usos tradicionais em áreas protegidas, como agricultura, pesca e mineração artesanal (PARREIRAS, 2018). Embora essas atividades viessem sendo realizadas há várias gerações e o Estado as tivesse tolerado como direitos costumarias, houve tentativas de classificá-las como irregulares (no sentido de violação de regras) ou mesmo ilegais, ao invés de informais. Dessa forma, a indenização está sendo questionada ou ignorada.

Outro problema é a redução da vida dos ribeirinhos a atividades que são sua principal fonte de renda. No entanto, um pescador tradicional ou um garimpeiro de ouro ou pedras preciosas não pode ser comparado a um trabalhador numa sociedade moderna baseada na divisão do trabalho. Nos territórios que ocupam, eles estão enraizados em um modo de vida que inclui uma variedade de atividades não monetárias. $\mathrm{O}$ rio e a terra em suas margens fazem parte de seu metabolismo territorial, do qual precisam para realizar seu modo de vida (LASCHEFSKI, ZHOURI, 2019). Reduzi-los a uma ocupação ilegal ou irregular torna possível excluí-los das reparações. Portanto, não é de surpreender que, quase quatro anos após o desastre de Mariana, 650 garimpeiros e pescadores que viviam ao longo do Rio Doce não tenham sequer recebido auxílio emergencial. Os ribeirinhos já romperam várias vezes as barreiras erguidas pela Samarco e pela Renova para chegar ao rio e retomar suas vidas (PARREIRAS, 2018). Em junho de 2019, com apoio do Movimento dos Atingidos por Barragens (MAB), ocuparam o escritório da Renova em Mariana, pois estavam sofrendo cada vez mais com a fome (PIZARRO, ARIADNE, 2019). Embora o pedido dos ribeirinhos de receber uma cesta básica mensal, no valor de R \$ 424,85 (DIEESE, 20192), fosse muito modesto, foram necessários 23 dias de ocupação e duas visitas de uma delegação da Renova para que chegassem a um acordo, que prevê, também, a inclusão da categoria como atingidos no cadastro (CARITAS, 2019).

3.1.2 O 'sistema perito de deslegitimação’ das vítimas e seus assessores

Outra estratégia da Samarco/Renova, também aplicada pela Vale em Brumadinho, é o estabelecimento do que chamamos aqui de sistemas peritos para deslegitimação das vítimas. Como é impossível conhecer todas as vítimas em desastres dessa magnitude, podemos, de acordo com

2 DIEESE, Departamento Intersindical de Estatística e Estudos Socioeconômicos. Custo da cesta básica diminuiu em 13 capitais. Disponível em: https://www.dieese.org.br/analisecestabasica/2019/201905cestabasica.pdf. Acesso em: 07 Jul. de 2019. 
Giddens (1990), entendê-las como um sistema abstrato no contexto da gestão de catástrofes. Tal sistema precisa ser avaliado por especialistas confiáveis que possam confirmar ou refutar a legitimidade das reivindicações das vítimas, por meio de fichas simbólicas (symbolic tokens), definidas como "meios de intercâmbio que podem ser circulados sem ter em vista as características específicas dos indivíduos ou grupos que lidam com eles em qualquer conjuntura particular" (GIDDENS, 1990, p. 22). Como no presente caso os especialistas são, normalmente, pagos pela Renova, cujo conselho fiscal é composto por representantes da Samarco, BHO-Billiton e Vale, sua tarefa é detectar aspectos que atestem a "inconfiabilidade" de certos grupos, a fim de questionar seus pedidos de indenização (o que, naturalmente, é de grande interesse para as empresas). Mas, por razões de credibilidade na comunicação com um público mais amplo, é necessário um mecanismo de desencaixe - dissembbedding, segundo Giddens (1990) - da situação real das vítimas, alcançado pela objetivação de sua elegibilidade para serem consideradas no processo de reparação, a partir de critérios preexistentes ou posteriormente inventados.

Um exemplo de critério preexistente, aplicável ao caso dos ribeirinhos atingidos pelos desastres em questão, é o reconhecimento da população local como "comunidade tradicional", condição descrita na Constituição Federal (BRASIL, 1988) e que garante especial atenção no processo de reparação. Portanto, são necessários alguns conhecimentos especializados para qualificar formalmente esses pescadores e faiscadores como "comunidade tradicional", uma vez que eles têm modos de vida específicos, entrelaçados com as condições físicas do território que habitam.

Um exemplo de abordagem do sistema perito para deslegitimação das vítimas pode ser observado no Relatório sobre povos tradicionais dos municípios de Rio Doce e Santa Cruz de Escavaldo/MG, elaborado pela Consultoria Campo - Cultura, Meio Ambiente e Patrimônio. A Renova contratou essa empresa para fornecer subsídios para a verificação da legitimidade das reivindicações de Ajuda Financeira Emergencial (AFE) feitas pelas famílias de garimpeiros e pescadores das comunidades do Rio Doce e Santa Cruz do Escalvado (RENOVA, 2019b). As reivindicações foram baseadas em estudos de campo realizados pela equipe de Mapeamento de Povos e Comunidades Tradicionais, coordenada pelo professor Aderval Costa Filho, antropólogo da UFMG. O pesquisador foi contratado como perito do caso por recomendação dos Ministérios Públicos Federal e Estadual e por exigência das Comissões de Atingidos.

No entanto, o "parecer técnico-antropológico" da consultoria Campo, com base apenas em atas e documentos fornecidos pela Fundação Renova, sem realização de trabalhos de campo, questiona os métodos "para verificação de tradicionalidade" utilizados pela equipe de Costa Filho (RENOVA, 2019b). Em suas recomendações, a consultoria Campo utiliza categorias jurídicoformais e dados genéricos do censo para negar os direitos das vítimas. É importante ressaltar que foi o acordo firmado entre Comissões dos Atingidos, Assessoria Técnica, Ministério Público Federal e 
Estadual e a Fundação Renova que originou o processo de autorreconhecimento em pauta. Além disso, a AFE referiu-se especificamente à substituição parcial de renda em situação de calamidade e não tem qualquer relação com o processo de reconhecimento da tradicionalidade.

Embora, posteriormente, a Renova tenha aceitado formalmente que a concessão do AFE fosse dissociada da conclusão dos trabalhos periciais, até o momento não houve qualquer providência no sentido de pagamento desse auxílio às famílias atingidas que integram coletivos e comunidades tradicionais.

Outros pesquisadores diretamente contratados pela Fundação Renova relataram que, embora não tivessem interferência no trabalho, parte dos dados coletados não foram considerados. Como, devido às condições contratuais, a Renova tem os direitos sobre os dados, as informações não podem ser utilizadas para qualquer outro fim. Essas dificuldades atrasam ou mesmo impedem o reconhecimento das comunidades tradicionais, o que significa também, obviamente, que os seus requerimentos de reparação podem ser rejeitados.

Em janeiro de 2016, em uma das primeiras reuniões da Samarco com os atingidos, observamos a classificação hierárquica das vítimas de acordo com critérios posteriormente inventados. O nível educacional foi utilizado como critério para identificar os representantes de determinados grupos, bem como os mediadores no diálogo entre a comunidade e a empresa. As vítimas "não-classificadas" foram manipuladas pelo argumento de "acelerar a busca de soluções", de tal forma que elas mesmas decidiram, em votação, que não podiam se expressar durante as reuniões. Os representantes da Samarco ainda se apropriaram de uma divisão da International Finance Corporation, entidade operacional do Banco Mundial que distingue deslocados físicos deslocalização ou perda de moradia - de deslocados econômicos - perda de bens ou acesso a bens (incluindo terras) que impliquem a perda de fontes de rendimento ou outras formas de reprodução social (IFC, 2012), para estabelecer níveis de urgência de atendimento diferenciados. Ao longo dos anos, surgiram, aleatoriamente, outras diferenciações: entre moradores do núcleo dos povoados destruídos e sitiantes, entre moradores de Paracatu de baixo e de cima; e, finalmente, entre urbanos e rurais. Essa última diferenciação se deveu ao fato de os moradores rurais não aceitarem a troca das terras extensas que perderam por lotes urbanos minúsculos com o mesmo valor monetário (Reunião da RENOVA com atingidos do rompimento da barragem em Mariana, em julho de 2019). Mesmo quando se tratava de escolher o terreno para reassentamento, apenas os chefes de família podiam votar, procedimento justificado pela empresa com o argumento da necessidade de acelerar a contagem dos votos.

Ainda mais preocupante é o fato de haver, nos questionários cadastrais, perguntas sobre o engajamento dos entrevistados em associações e entidades religiosas e políticas, assim como sobre suas opiniões relativas aos líderes comunitários e pessoas que, possivelmente, poderiam se 
beneficiar da situação. Em um clima geral de medo de que não haja recursos suficientes para a reparação de todos, essas divisões artificialmente criadas levam a conflitos internos e até mesmo à exclusão de indivíduos que supostamente não têm direito à indenização.

O sistema perito para deslegitimação delineado acima se aplica igualmente à seleção das entidades de assistência técnica. Tudo começou com o questionamento das primeiras atividades da Samarco pela sociedade civil. O foco foi no conflito de interesses das consultorias contratadas, que atuam entre a preocupação de atender os interesses da empresa que as paga e a necessidade de um levantamento independente dos danos e valores, visando à reparação justa das vítimas. Esse foi o ponto de partida para o estabelecimento de um sistema de governança multi-stakeholder, que hoje é representado pela Renova.

Contudo, a Samarco está, por sua vez, questionando a capacidade técnica e a neutralidade das entidades de assistência técnica recomendadas pela sociedade civil, uma vez que muitas delas tinham orientação política definida. Finalmente, foram estabelecidos, pelo TAC Governança, alguns critérios para a escolha das assistências técnicas.

Cabe lembrar que a perspectiva dos recursos disponíveis nas 42 linhas de ação da Renova tem gerado uma corrida concorrencial entre instituições da sociedade civil, consultorias, institutos de investigação e universidades. Observa-se, tanto no caso do desastre em Mariana como em Brumadinho, que muitos conflitos surgem porque diversas prestadoras de serviços, grupos voluntários, entidades da sociedade civil, iniciativas partidárias e igrejas estão vinculando as atividades de apoio às vítimas a agendas próprias, o que gera contradições e situações conflituosas, além de fragmentação das atividades. Um exemplo dessa situação é o Movimento dos Atingidos por Barragens (MAB), que é, sem dúvida, uma das organizações mais importantes na luta pelos direitos das vítimas, mas que, em muitos lugares, perdeu o apoio das pessoas afetadas porque realizou ações que não estão relacionadas às suas preocupações imediatas. Assim, observamos um esvaziamento da Marcha dos Atingidos de Regência - ES a Mariana - MG, 1 Ano de Lama e Luta, realizada entre 31 de outubro e 5 de novembro de 2016, porque as falas foram, segundo as vítimas participantes, mais centradas nas questões de conjuntura política geral do que na sua situação pessoal.

Nesse problema, que outras organizações também enfrentam, evidencia-se, portanto, uma perda do foco: as vítimas são um grupo heterogêneo, cujos integrantes se distinguem pela cor de sua pele, por crenças políticas, ideológicas e religiosas, por rendimentos e bens ou pelo pertencimento a determinada classe social. Elas têm apenas duas coisas em comum: o desejo de reconstruir suas vidas e, de acordo com o princípio da dignidade humana garantido pela Constituição, o direito a uma justa reparação pelos danos materiais e imateriais. Verificamos, também, uma perda de foco na atuação de muitos pesquisadores, que visitam as áreas devastadas na esperança de achar uma 
espécie de laboratório para realizar pesquisas ou aplicar, e até vender, métodos desenvolvidos por eles.

Finalmente, queremos salientar o risco de instrumentalização das universidades públicas dentro do campo da governança. A título de exemplo, salientamos o Edital formulado claramente pela Renova e administrado pela Fundação de Amparo à Pesquisa do Estado de Minas Gerais (FAPEMIG). Essa Fundação agiu como uma empresa terceirizada pela Renova, assumindo a tarefa de seleção dos pesquisadores, os quais, por sua vez, acreditaram que estavam concorrendo a recursos públicos. Contudo, nesse Edital, as questões de pesquisa e os planos de trabalho têm que atender aos requisitos da Renova, que conseguiu reduzir os custos das consultorias por meio de parcerias com as universidades que, devido aos seus escassos recursos, realizam os trabalhos por intermédio de bolsistas e orientandos.

Outro exemplo se refere ao desastre em Brumadinho. Um Termo de Audiência na $6^{\text {a }}$ Vara da Fazenda Pública e Autarquias da Comarca de Belo Horizonte, publicado no dia 21 de maio 2019, sobre um projeto extensão intitulado Prestação de Serviço - Projeto de Avaliação de necessidades pós-desastre do colapso da barragem da Mina do Feijão, firma uma parceria entre o Ministério Público, pesquisadores da UFMG e a própria Vale, estabelecendo que "os projetos apresentados pelo Comitê Técnico-Científico serão avaliados e aprovados pelo MM. Juiz após oitiva das partes [...]" (PODER JUDICIÁRIO DE MINAS GERAIS, 2019). Essa redação é problemática porque, se as universidades querem atuar de acordo com a Constituição Federal para salvaguardar a dignidade humana, elas devem - assim como os tribunais e os promotores públicos - evitar qualquer possibilidade de interferência por parte das empresas. O conteúdo e a condução das atividades estão nas mãos de um juiz que, aparentemente, pretende "pacificar" resultados conflitantes de pesquisas. 3 Essa forma de governança, ao interpretar o trabalho dos pesquisadores como "interesses" específicos a serem negociados em um esquema de mediação que inclui a própria Vale, corre o risco - semelhante à situação protagonizada pela RENOVA - de contradizer os direitos constitucionais que garantem a reparação integral dos danos. Além disso, os pesquisadores envolvidos no projeto renunciam à autonomia da pesquisa, ao controle sobre seus planos de trabalho e à publicação dos resultados, o que é garantido pelos artigos 206 e 207 da Constituição Federal de 1988 e pelo artigo $3^{\circ}$ do próprio Estatuto da UFMG de 1999.

Outro aspecto importante é que a Vale já usou o projeto Brumadinho mesmo antes do início das atividades na UFMG segundo a lógica do "sistema perito de deslegitimação", a fim de desacreditar o trabalho em andamento da assistência técnica de grupos da sociedade civil. Os advogados da empresa apresentaram no âmbito do Processo $n^{\circ}$ 5010709-36.2019.8.13.0024 - que

3 Fala do juiz da $6^{\text {a }}$ Vara de Fazenda Pública e Autarquias de Belo Horizonte, Elton Pupo Nogueira, durante o projeto Prestação de Serviço - Projeto de Avaliação de necessidades pós-desastre do colapso da barragem da Mina do Feijão, em 01/11/2019, no Auditório Rodrigo Ferreira Simões, Faculdade de Ciências Econômicas - FACE/UFMG. 


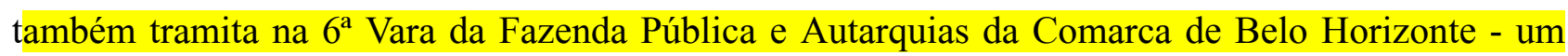
documento que questiona o "Plano de Trabalho de Assessoria Técnica" der Associação Estadual de Defesa Ambiental e Social - AEDAS:

\begin{abstract}
Apresentada a primeira proposta de trabalho da AEDAS, a posição da VALE foi contundente: era necesário readequar o conceito da proposta, considerando (a) o cronograma projetado, de modo a atender expectativas desse MM. Juízo, das partes e, principalmente, dos impactados, (b) a necessidade de se evitar a sobreposição com os demais trabalhos que vẽm sendo desenvolvidos perante esse MM. Juízo, especialmente pela Universidade Federal de Minas Gerais ("UFMG"), (c) a coerência dos trabalhos propostos com o objetivo da assessoria técnica e a sua expertise, (d) a importância de se detalhar, com minúcia, as atividades e a qualificação dos profissionais a serem mobilizados... (TJMG, 2019, grife nosso).
\end{abstract}

Nesse contexto, a empresa faz referência equivocada à UFMG, pois a parceria foi estabelecida apenas com um número limitado de professores que não têm mandato para representar a comunidade científica inteira a instituição. O princípio constitucionalmente garantido da autonomia e liberdade de pesquisa como base da produção de conhecimento permite que os cientistas submetam seus resultados de pesquisa à discussão científica, mas não lhes dá o direito de apresentá-los como a "verdade oficial" única da universidade. Portanto, os resultados do projeto Brumadinho também podem ser questionados - dentro das regras do rigor científico - por outros cientistas da instituição, o que por sua vez impede que os participantes do referido projeto falem em nome da UFMG como um todo.

Por fim, vale lembrar que, evidentemente, a Renova e a Vale se beneficiam das parcerias com universidades e instituições públicas, não apenas por custos de terceirização, mas também porque isso melhora sua imagem e credibilidade em suas campanhas publicitárias.

\title{
3.1.3 Recuperação ambiental: natureza itinerante e hidden landgrabbing
}

A última estratégia que identificamos como meio de acumulação por despossessão diz respeito a uma questão que parece pouco controversa: grande parte dos fundos investidos pela Renova foram destinados à recuperação de áreas afetadas pela lama. Declarações como "o meio ambiente e as pessoas vão ficar melhores do que estavam antes", como disse o então presidente da Vale, Fabio Schvartsman, em 2018 (CAMARGOS, 2018), estão baseadas na crença que seria possível enfrentar até mesmo os piores desastres em solo brasileiro com a utilização de meios tecnológicos para mitigação e compensação dos danos ambientais. Essa forma de pensar, que permeia todo o planejamento ambiental, reflete a ideia de natureza itinerante (análoga à de agricultura itinerante) que, em última instância, permite que até mesmo os métodos de uso da terra mais prejudiciais ao meio ambiente sejam declarados ecologicamente viáveis. No entanto, em 2016, 
registramos a insatisfação dos moradores de Bento Rodriguez e Paracatu com as leguminosas que foram semeadas na lama que cobria suas casas para acelerar a restauração da cobertura vegetal. Os habitantes entendiam tal medida, por um lado, como uma invasão ilegítima de suas terras e, por outro, como um impedimento às escavações realizadas pelas famílias em busca dos pertences remanescentes. Chamou nossa atenção o fato de as medidas de recuperação do ambiente estarem sendo aplicadas em territórios anteriormente utilizadas pelas vítimas, incluindo áreas de uso comum sem títulos de propriedade. Em três entrevistas com especialistas em recuperação ambiental de áreas de mineração da Alemanha, convidados pela Fundação Getúlio Vargas, em janeiro 2018, para apresentar propostas para o Vale do Rio Doce, verificamos que lhes faltava um olhar mais apurado para as comunidades rurais que reivindicam as roças de volta nas áreas afetadas pela lama. Em visitas de campo, percebemos a prevalência de medidas de recuperação guiadas pela visão de "natureza sem gente", segundo a qual apenas atividades como o ecoturismo são admitidas. Enquanto não houver clareza sobre o uso prévio dessas áreas pela população afetada, as medidas de renaturalização podem levar a uma apropriação oculta dos territórios tradicionais (hidden landgrabbing). 
Foto 2: Recuperação ou hidden landgrabbing?

Campo de futebol, Paracatu, destruido pelo colapso da barragem Fundão, Mariana, MG.
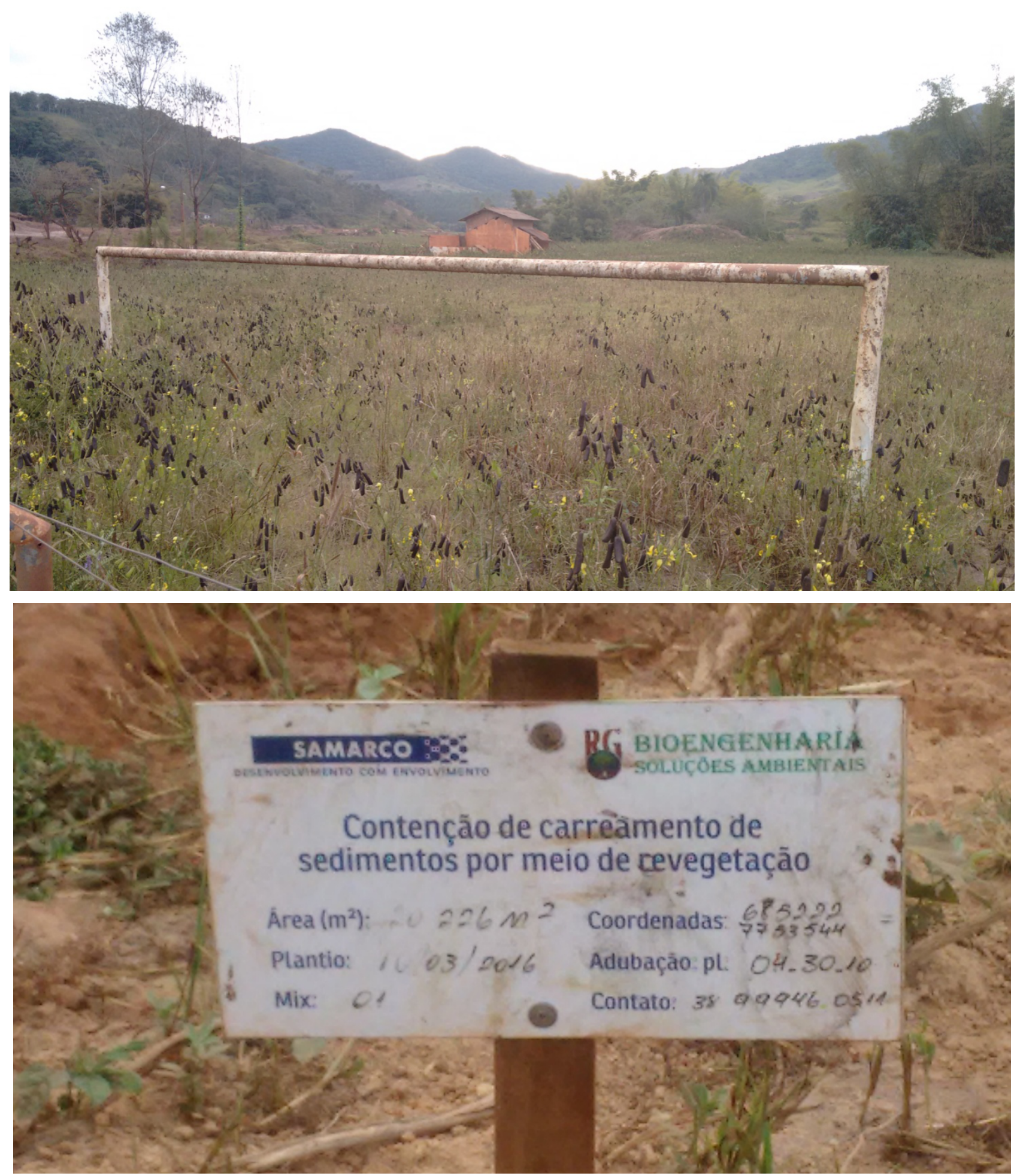

Laschefski, 2016 


\section{O desastre de Brumadinho}

Como mencionado, após o rompimento da barragem de Mariana, a legislação ambiental foi flexibilizada pela Lei $\mathrm{n}^{\circ} 21.972$, que criou a SUPPRI. Diante disso, entendemos que o desastre em Brumadinho começa com a concessão da licença ambiental para os projetos de mineração, que incluem as barragens de rejeitos do Córrego do Feijão. Aliás, o processo de licenciamento foi um exemplo de como aplicar os novos regulamentos. Nesse, como em outros casos de mineradoras, a SUPPRI utilizou, com bastante empenho, um novo instrumento: a Deliberação Normativa COPAM 217/17, que possibilita a reclassificação do potencial poluidor dos projetos. Isso fica claro no comunicado feito à imprensa, aos pesquisadores e aos movimentos sociais sobre a $36^{\mathrm{a}}$ Reunião Ordinária da Câmara de Atividades Minerarias (CMI/COPAM), realizada em 30 de novembro de 2018, que se refere, entre outros, à barragem do Córrego do Feijão da Vale S.A., que rompeu um mês e meio depois:

Os conselheiros vão deliberar sobre mega-empreendimentos de mineração de ferro que foram re-enquadrados, repentinamente, da classe 6 (grande porte e potencial poluidor) para classe 4 (médio impacto ambiental) segundo a nova "Deliberação Normativa COPAM 217/17" que vigora desde março. Grandes complexos minerários como o da Anglo American sempre foram enquadrados na classe $6 \mathrm{e}$ agora estão na pauta como classe 4 e ainda podem ser licenciados com licenças concomitantes, inclusive três de uma só vez, chamada LAC1 (Licença Prévia, Licença de Instalação e Licença de Operação), quando antes teria que ser um licenciamento trifásico. Os projetos de ampliação e continuidade até 2032 da minas da Jangada (Minerações Brasileiras Reunidas S.A.) e do Córrego do Feijão (Vale S.A.), além de estarem enquadrados como classe 4 estão com a modalidade LAC1, apesar de ambos estarem localizados na zona de amortecimento do Parque Estadual da Serra do Rola Moça (criado para a proteção de aquíferos importantes dos municípios de Brumadinho, Ibirité e da zona sul de Belo Horizonte) que pelo critério locacional implica na modalidade LAC2 (duas licenças concomitantes)

Na reunião do dia 30, Rodrigo Ribas, Superintendente de Projetos Prioritários (SUPPRI), banalizou a falha na classe informada nos processos de licenciamento das minas Jangada e Feijão atribuindo o fato a "um erro de digitação na pauta da reunião". É importante ressaltar que, poucos dias antes, em 19 de novembro de 2018, na reunião do Conselho do Parque Estadual da Serra do Rola Moça, os dois projetos foram tratados como enquadrados na Classe 6. Com isso, o Sr. Rodrigo Ribas esqueceu o princípio da publicidade, o que, por si só, justificaria a retirada desses processos da pauta daquela reunião da CMI, pedido esse feito pela conselheira Maria Teresa Corujo do Fórum Nacional de Comitês de Bacias Hidrográficas (FONASC).

Contudo, o presidente da reunião, Yuri Rafael de Oliveira Trovão, acatou todos os argumentos apresentados pelo Superintendente da SUPPRI para negar o pedido da conselheira. Assim, a conselheira do FONSAC pediu vistas para consultar todos os documentos, preparar parecer sobre os dois processos de licenciamento e averiguar a possibilidade de instaurar a apuração de crime de responsabilidade para aqueles que se omitiram ou decidiram não realizar o controle de legalidade em relação aos processos supracitados (MOVSAM, 2018). 
Foto 3: 36a Reunião da CMI/COPAM, 05 decembro 2018, no momento do anúncio do "erro de digitação" em relação à "classe de potencial poluidor" do projeto Jangarda/Corrgo do Feijão

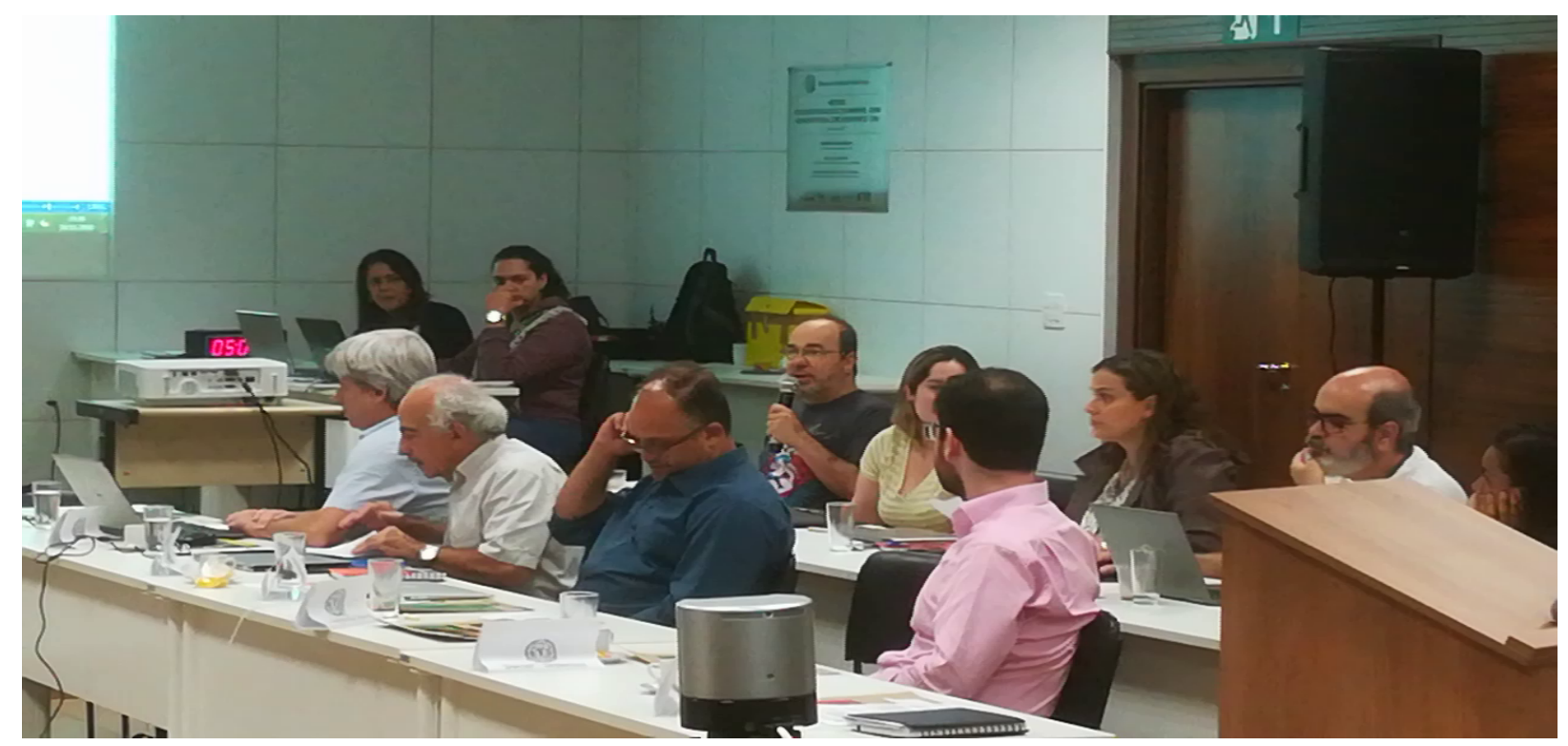

Laschefski, 2018.

Contudo, na 37 Reunião da CMI/COPAM, realizada em 11 de dezembro de 2018, a proposta de conceder uma Licença Prévia concomitante às licenças de Instalação e de Operação das minas Jangada (Minerações Brasileiras Reunidas S.A.) e Córrego do Feijão (Vale S/A), que incluem a "lavra a céu aberto sem tratamento ou com tratamento a seco", suscitou novas controvérsias. Isso porque a SUPPRI justificou a simplificação do processo com o suposto efeito ambiental positivo da desativação da barragem de rejeitos, embora o projeto envolvesse, principalmente, uma ampliação da produção de minério em $88 \%$ nas duas minas.

O projeto foi aprovado com apenas um voto contrário da Conselheira Maria Teresa Corujo e a abstenção do Conselheiro Julio César Dutra Grillo, do Instituto Brasileiro do Meio Ambiente e dos Recursos Naturais Renováveis (IBAMA), pelos seguintes motivos:

Agora, falando sobre [...] os motivos da minha abstenção, esse projeto traz algumas novidades positivas. Uma delas é o descomissionamento de uma barragem de 10 milhões de $\mathrm{m}^{3}$ que está acima de Casa Branca. A população de Casa Branca está preocupada com muitas coisas, com toda razão, mas não manifesta preocupação sobre aquilo que eu considero que é potencialmente o maior problema de Casa Branca. O que é esse problema? Casa Branca tem algumas barragens acima de sua cabeça. Muita gente aqui citou o problema de Mariana, de Fundão, e vocês têm um problema similar. E ali é o seguinte, essas barragens não oferecem risco zero. Em uma negligência qualquer de quem está à frente de um sistema de gestão de risco, aquilo rompe. Se essa barragem ficar abandonada alguns anos, não for descomissionada, ela rompe, e isso são 10 milhões $\mathrm{de}^{3}$, é um quarto do que saiu de Fundão, inviabiliza Casa Branca e inviabiliza ao menos uma das captações do 
[sistema de abastecimento de água] Paraopeba (Conselheiro Julio Cesar Dutra Grillo, ao justificar o seu voto na $37^{\circ}$ da CMI/COPAM, $\left.12 \mathrm{dez} 2018\right)$.

Note-se que o tema do descomissionamento das barragens a montante tem sido frequentemente discutido no CMI/COPAM e o risco imediato de colapso da barragem do Córrego do Feijão já era de conhecimento geral.4 Entretanto, o questionamento dos representantes da sociedade civil presentes na reunião sobre a corrida repentina para licenciar a significativa expansão das atividades de mineração na região, que incluiu a barragem Córrego do Feijão, permaneceu sem resposta. $\mathrm{O}$ mesmo aconteceu com relação à provocação de que esse procedimento não serve nem aos interesses da sociedade civil nem às instituições públicas, mas apenas às empresas de mineração (CMI/COPAM, 2018).

A resposta pode estar na compra da empresa New Steel soluções sustentáveis S.A. pela VALE S.A., por USD 500 milhões, no mesmo dia da aprovação das licenças para os projetos em Brumadinho. A New Steel possui, atualmente, patentes de tecnologia de separação magnética de finos a seco (em inglês, Fines Dry Magnetic Separation - FDMS), em 52 países, e, segundo artigo publicado em 7 de janeiro de 2019, no portal In The Mine, desenvolveu uma inédita tecnologia industrial de aproveitamento de minério a seco:

Esse método de beneficiamento promete elevar em até $66 \%$ teores de ferro inicialmente abaixo de $50 \%$, separando magneticamente - com uso de gás natural ou biomassa - o ferro da sílica, sem a geração de rejeitos. Em setembro de 2017, a New Steel obteve a Licença de Instalação (LI) para uma usina de beneficiamento a seco em Ouro Preto (MG), dentro da Mina Fábrica, da Vale - onde já possuía uma planta piloto funcionando desde 2015. A unidade processará o minério de ferro marginal e os rejeitos da mina, através de secadores industriais com injeção de ar quente, movidos a gás natural. A operação está prevista para 2019, com produção inicial de 1,3 Mtpa e recuperação da ordem de 52\%. Agora, tudo está em casa. $A$ Vale, inclusive, acaba de receber a LI para a expansão das minas de Jangada e Córrego do Feijão, em Brumadinho e Sarzedo, de 10,6 para 17 Mtpa. O projeto inclui a recuperação de finos das Barragens I e VI de Córrego do Feijão e a implantação de um rejeitoduto pra transporte do material às usinas de beneficiamento (ITMNEWS, 2019, grifos nossos).

4 Após o rompimento da barragem em Brumadinho, a Policia Federal entregou ao Ministério Público de Minas Gerais (MPMG) uma lista interna da Vale, elaborada em 2018, indicando as barragens em risco: barragem Laranjeiras, em Barão de Cocais (MG); as barragens Capitão do Mato, Dique B e Taquaras, em Nova Lima (MG); as barragens Forquilha I, Forquilha II e Forquilha III, em Ouro Preto (MG) e as barragens I, IV e Menezes II da Mina do Feijão, em Brumadinho (RODRIGUES, 2019). Além disso, consta na Recomendação $N^{o}$ 11/2019, conjunta da Procuradoria Federal de Minas Gerais, Ministério Público Estadual e Polícia Federal de Minas Gerais, que o estado crítico da estabilidade da Barragem B1 no complexo minerário Córrego do Feijão já foi discutido no seminário Independent Panel of Experts for Safetyand Risk Management of Geotechnical Structures (Piesem) - Painel de Especialistas para o Gerenciamento de Segurança e Risco de Estruturas Geotécnicas -, de novembro de 2017. O seminário recomendou expressamente que a Vale adotasse para suas barragens um fator de segurança maior ou igual a 1,3, quando em condição não-drenada. Posteriormente, as consultorias responsáveis pela avaliação da estabilidade da barragem, a Potemos e a Tractebel se recusaram a emitir uma declaração favorável ao empreendimento diante de um fator de 1,09. Isso resultou na substituição imediata da Tractebel pela TüvSüd, que estava disposta de atestar a segurança, apesar do pleno conhecimento da situação da barragem (MPF/MPE/PF, 2019). 
Embora a Vale tenha negado essa ligação após o colapso da barragem B15, há muitas indicações de uma estratégia planejada para entrar em novos mercados, o que explica a corrida por licenças ambientais para um grande número de barragens. Em 29 de janeiro de 2019, apenas cinco dias após do desastre criminoso de Brumadinho, a empresa anunciou o fechamento de mais 10 barragens do mesmo tipo. O plano para isso já estava pronto, fruto de um acordo com os governos federal e estadual, com participação dos órgãos ambientais competentes. Segundo o então presidente da Vale, Fabio Schvartsman, “[...] não teve qualquer tipo de pressão" (INFOMONEY, 2019). No dia seguinte a esse pronunciamento, a Secretaria do Meio Ambiente publicou a Resolução Conjunta SEMAD/FEAM no 2.765, de 30 de janeiro de 2019, que determina que as barragens de rejeitos de mineração que utilizem ou que tenham utilizado o método de alteamento a montante deverão ser descaracterizadas no prazo máximo de dois anos.6 Como resultado, novos mercados lucrativos foram abertos para a Vale, já que qualquer mineradora que deseje extrair o minério remanescente durante a desativação das barragens precisará da tecnologia FDMS desenvolvida por sua nova subsidiária, a New Steel. Portanto, não é realmente surpreendente que o anúncio acima tenha provocado, naquele dia, uma recuperação de 8,5\% nas ações da Vale (STAR ONLINE, 30 Jan 2019). A hipótese de que o "plano de emergência" apresentado pela Vale teria sido elaborado antes da ocorrência fatal em Brumadinho também é sustentada pelos seguintes pontos:

Desde 2015, a Vale desenvolve importantes projetos de construção de barragens de rejeitos, como a barragem Brucutu Norte (2015) e a barragem Forquilha V (2016), em Minas Gerais, e novos projetos foram iniciados, como a barragem Maravilhas III (2016), também em Minas Gerais. É importante ressaltar que todas as novas construções de barragens da Vale seguem o método de construção convencional, em linha com a decisão tomada em 2016, após a ruptura da barragem da Samarco em Mariana, de desativar e descomissionar todas as barragens a montante, que será acelerada conforme o Press Release de 29 de janeiro de 2019.

O plano da Vale é aumentar a participação do processamento a seco em sua produção para $70 \%$ até 2023 e, consequentemente, reduzir o uso de barragens em suas operações. Além disso, para tratar os rejeitos de seu processamento úmido, a Vale informa que planeja investir, a partir de 2020, aproximadamente R $\$ 1,5$ bilhão (cerca de US\$ 390 milhões) na implantação da tecnologia de disposição de pilhas secas. Essa iniciativa acompanha a aquisição da New Steel anunciada em 11 de

5 Em junho de 2019, após a Comissão Parlamentar de Inquérito (CPI) da Barragem de Brumadinho, da Assembleia Legislativa de Minas Gerais (ALMG), ter levantado a questão da possível corrupção em relação à compra do NEW STEEL, a Vale esclareceu que não havia qualquer relação com a barragem do Córrego do Feijão. Por meio de nota emitida no dia 3 de junho de 2019, a empresa afirma: "Sobre o rejeito retido no entorno da Barragem I, a Vale não pretende reaproveitá-lo. Conforme já informado aos órgãos públicos, a empresa irá recuperar ambientalmente toda a área impactada pelo rompimento" (SOUZA, 2019). Deve-se lembrar que existem óbvias dificuldades técnicas na utilização do lama derramado ao longo do vale do Rio Paraopeba; com essa declaração, a Vale quer desviar a atenção da intenção original citada acima.

6 Esta resolução foi posteriormente revogada pela Decisão Conjunta SEMAD/FEAM n. ${ }^{\circ}$ 2.784, de 21 de Março de 2019. O artigo $2^{\circ}$ estipula: "No caso das barragens de mineração que utilizem o método de alteamento a montante em operação, os empreendedores que optarem pela continuidade da atividade, deverão migrar para a tecnologia alternativa de acumulação ou disposição de rejeitos, nos termos do $\S 2^{\circ}$ do art. 13 da Lei n ${ }^{\circ} 23.291$, de 2019, observando o prazo máximo de três anos, contados da data de publicação dessa lei." 
dezembro de 2018, com tecnologias inovadoras para o beneficiamento a seco de minério de ferro (MOORE, 2019, tradução própria).

Após a liberação das licenças para a expansão da mineração em Brumadinho, os moradores observaram aumento de movimentação de veículos tanto nas minas quanto nas barragens. De acordo com relatórios não confirmados, as medidas para drenar o reservatório de rejeitos falharam. O fato é que, logo antes do rompimento da barragem, foram realizadas " [...] leituras inconsistentes em diversos piezômetros instalados no maciço da barragem B1" (MPF/MPE/PF, 2019). Mesmo assim, as atividades das mineradoras não foram suspensas e não houve evacuação das áreas potencialmente afetadas. Diante disso, certamente, o desastre de Brumadinho pode ser visto, no mínimo, como uma tentativa malsucedida de iniciar a estratégia descrita acima.

Parece, no entanto, que a Vale se recuperou rapidamente do choque. Pouco depois da divulgação da lista das 10 barragens de risco, a empresa apressou-se em explicar que não havia perigo imediato de outro desastre (RODRIGUES, 2019). No entanto, quando o debate público sobre a segurança dos moradores nas chamadas 'zonas de autossalvamento' abaixo das barragens levou à adoção da Lei 23.291, de 25 de fevereiro de 2019 (Lei Mar de Lama nunca mais), seu comportamento mudou. Nas zonas de autossalvamento das localidades afetadas, ela começou a sinalizar rotas de fuga, montar sirenes e preparar a população para emergências, por meio de treinamento. Mas não se tratava de uma estratégia civilizada para eliminar os riscos dos empreendimentos e preparar para eventuais evacuações temporárias, de modo a tranquilizar a população. Em vez disso, a Vale providenciou a classificação burocrática das barragens nos níveis mais altos de risco e, então, na madrugada, sem qualquer necessidade real, deixou as sirenes uivarem. Os movimentos sociais chamaram de "terrorismo das barragens" (MANUELZÂO, 2019) esse procedimento que deslocou milhares de pessoas nas cidades Itatiaiuçu, Barão de Cocais, Macacos, Nova Lima, Ouro Preto, Itabira, Itabirito, Congonhas e Rio Preto. Para os habitantes, seu lugar de vida cotidiana foi transformado, literalmente, da noite para o dia, em um território de medo, do qual eles queriam sair o mais rápido possível. 
Foto 4: Placas indicando rotas de fuga, os residentes mudaram a posição dos sinais em protesto
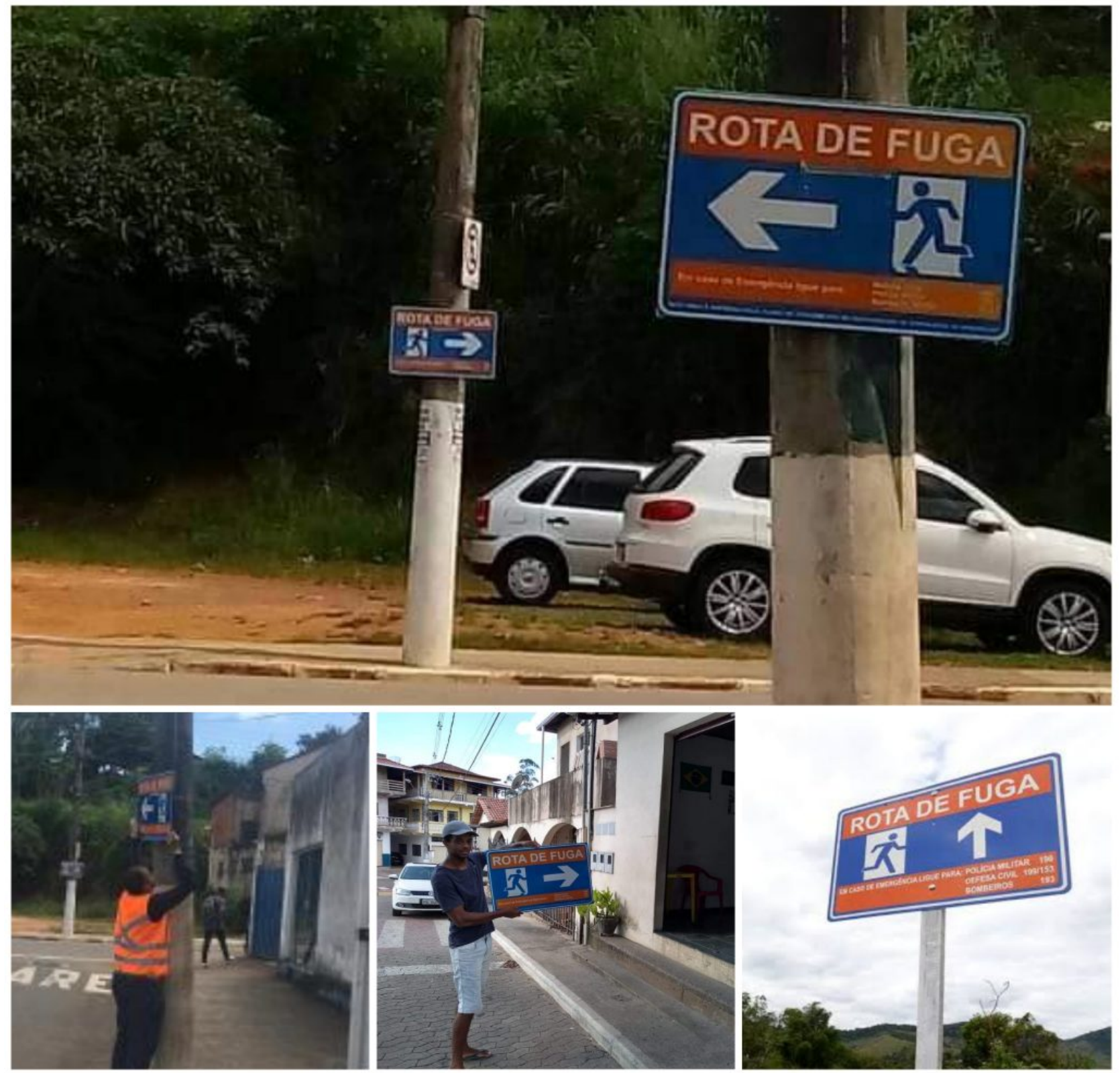

Itabira online, 04-01-2019, (Disclosure Defesa Civil).

Mas qual é a vantagem que a Vale tira disso? É importante lembrar que as barragens que estão atualmente classificadas como de alto risco são exatamente aquelas que a empresa pretende descomissionar. Para possibilitar a extração a seco do minério dos resíduos depositados, os reservatórios têm que ser drenados. Para isso, a empresa constrói, primeiro, diques convencionais abaixo das barragens perigosas para coletar a água proveniente da drenagem. Para viabilizar esse projeto, a Vale tem que fazer duas coisas: comprar terra e obter as licenças necessárias. A mera delimitação das zonas de autossalvamento já levou a uma redução considerável dos preços dos 
imóveis, o que, obviamente, facilita a sua aquisição. Os acontecimentos de Barão de Cocais mostram que a empresa obtém a necessária aprovação das autoridades utilizando o argumento da necessidade de construções emergenciais. Em 8 de fevereiro de 2019, depois de a barragem do Sul Superior, no complexo mineiro Gongo Soco, ter sido reclassificada para um nível de perigo mais elevado, a Vale fez uivar as sirenes às 4:00 da manhã e evacuou 487 pessoas (MANSUR, 2019), a maioria das comunidades de Socorro, Tabuleiro, Piteiras e Vila Congo, localizadas dentro da zona de autossalvamento. Em caso de ruptura, a avalanche de lama também afetaria o centro da cidade, com potencial de causar um desastre ainda mais grave do que o de Brumadinho. Em 20 de maio de 2019, a empresa informou à mídia que, além do perigo de liquefação da barragem, ocorreria, até o dia 26 do mesmo mês, a queda de um talude na cava da mina Gongo Soco, localizada a 1,5 km de distância. O tremor desse deslizamento de terra aumentaria em 10 a 15 por cento a probabilidade de rompimento da barragem (EXAME, 2019). Em 16 de junho de 2019, no entanto, a Vale anunciou o fim do perigo, declarando que "o momento corrobora as estimativas de que o desprendimento do talude deverá ocorrer sem maiores consequências" (G1 Minas, 2019a).

Já em março, a defesa civil anunciou que a Vale poderia ser forçada a construir um muro de contenção para proteger a cidade (MATTOS, 2019) e, em abril, o projeto de um dique de 35 metros de altura e 107 metros de cumprimento, localizado a $6 \mathrm{~km}$ a jusante de barragem Sul Superior, foi apresentado à população. A proposta desencadeou protestos, principalmente devido a dúvidas sobre a eficácia do muro em caso de catástrofe e à falta de proteção às quatro comunidades mencionadas, localizadas na área de abrangência do projeto. Embora o prefeito de Barão de cocais cidade tenha declarado que "depois de realizar o descomissionamento total da barragem, o muro seja demolido" (OLIVEIRA, 2019), há fortes indícios de que os moradores evacuados nunca mais poderão retornar às suas terras. Isso não só pela transformação dos seus terrenos em função das obras de construção, mas também pela tendência da empresa de apropriação de terrenos para outros interesses. Pelo menos oito moradores evacuados denunciaram à CPI de Brumadinho que, em 2011 e 2012, foram procurados pela VALE para assinar uma autorização para "Fins de Estudos Espeleológicos e Identificação de Cavidades" nas suas terras, o que indica que o verdadeiro interesse da empresa seria a exploração da área, rica em minério. O que causou estranheza é que a autorização foi dada ao setor de aquisição de compras de Imóveis da Vale (DE FATO, 2019). Em geral, a empresa de mineração já tentou, no passado, comprar terras na região por meios convencionais. Em 18 de maio de 2019, as dúvidas foram reforçadas por causa de uma decisão judicial que adotou moção da Vale para ocupar terras privadas na área de contenção e impôs multa diária de R\$ 10 milhões ao proprietário que descumprir essa ordem. A mineradora também solicitou que a ação fosse mantida em sigilo, mas este pedido não foi aceito pelo juiz (G1 MINAS, 2019b). 
Durante um estudo de campo em 21 e 22 de novembro de 2019, moradores evacuados relataram que estavam sob pressão crescente para vender suas terras. Eles são tratados de forma diferente dos "sitiantes", ou seja, proprietários de casas de fim-de-semana que vivem em Belo Horizonte e aos quais são oferecidos preços exorbitantes para os seus lotes. Mas como não querem vender porque "viver na cidade nos deixa triste" (entrevista com um morador de Socorro, 21/11/2019), a Vale usa estratégias semelhantes para desgastar e convencê-los a vender seus imóveis a preços baixos. Essas estratégias incluem o fomento de conflitos entre os grupos removidos e os moradores do centro urbano e, às vezes, ameaças abertas. 
Foto 5: Povoado Socorro, evacuado pela Vale e faixa de protesto dos moradores.
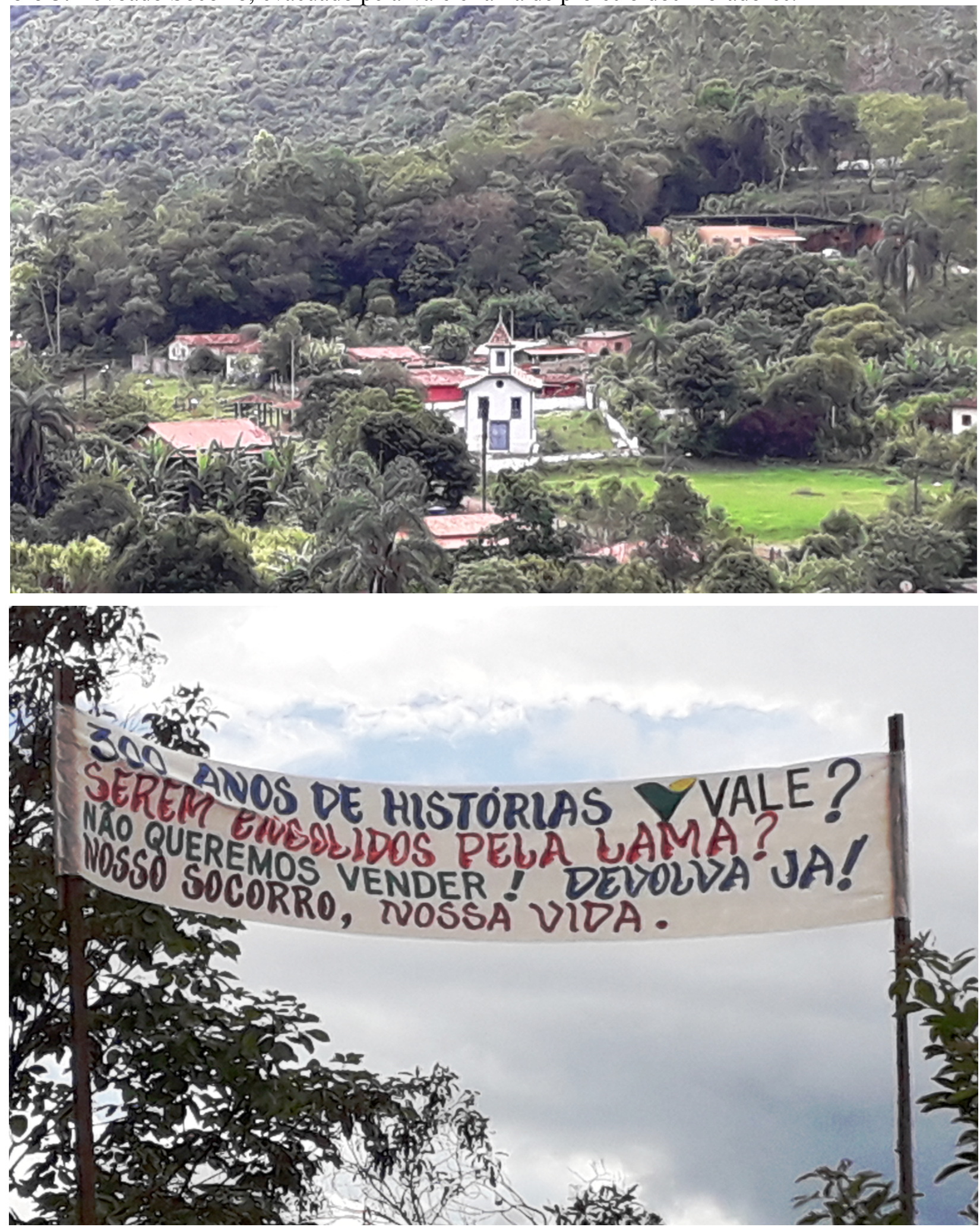

Laschefski, 2019

Tais acontecimentos foram acompanhados por uma forte articulação da empresa com os órgãos ambientais do Estado. Antes, no dia 8 de Fevereiro de 2019 (mesmo dia em que as sirenes 
soaram), a Vale anunciou à SUPPRI o início de "obras emergenciais para implementação de Estrutura de Contenção em Concreto Rolado - CCR à jusante a barragem Sul Superior" (Carta protocolada na SUPPRI/SEMAD, 09/04/2019, N 446/2019), inclusive da supressão de manchas de vegetação nativa do bioma da Mata Atlântica. A construção do muro não era, portanto, uma obrigação oficial da Vale, mas foi proposta pela própria empresa. Em denúncia encaminhada por Maria Teresa Corujo, do MOVSAM, tal procedimento gera ainda mais suspeitas, já que a Mina Gongo Soco consta nos Estudos de Impacto Ambiental (EIA) como estrutura associada às Minas Apolo e Serra do Gandarela. O processo parecia parado, pois a revalidação da licença de operação de Gongo Soco estava "sob análise” desde 2012. Nenhum dos documentos continha uma explicação técnica que justificasse a construção do muro a uma distância de 6 quilômetros da barragem. Chama a atenção, ainda, a licença para atividade da barragem do empreendimento ter sido suspensa também no dia 8 de fevereiro de 2019 (documento 0076584/2019), desburocratizando caminhos para as obras supostamente emergenciais.

No dia 6 de julho, foi oficializada a construção de mais um dique para possibilitar o descomissionamento das barragens B3/B4 da Mina Mar Azul, em São Sebastião das Águas Claras, conhecida popularmente como Macacos. Segundo a Vale, "por se tratar de uma obra emergencial, não há necessidade de licenciamento prévio" (VALE, 2019). Neste caso, as sirenes tocaram no dia 16 de fevereiro de 2019 e cerca de 200 pessoas foram evacuadas em área que abrange 49 edificações, entre domicílios e estruturas de uso comercial (FONTES, 2019). A barreira esta sendo erguida $8 \mathrm{~km}$ a jusante das duas barragens de rejeitos em risco e terá $200 \mathrm{~m}$ de comprimento, $80 \mathrm{~m}$ de largura e $30 \mathrm{~m}$ de altura. Para viabilizar essa estrutura, a Vale abriu uma estrada com $2,5 \mathrm{~km}$ de extensão (foto 6 ). 
Foto 6: "Obras emergências" justificadas pela ameaça da rompimento das barragens B3/B4 na mina Mar Azul, em São Sebastião das Águas Claras, localizadas em Áreas de Proteção Permanente (APP) .
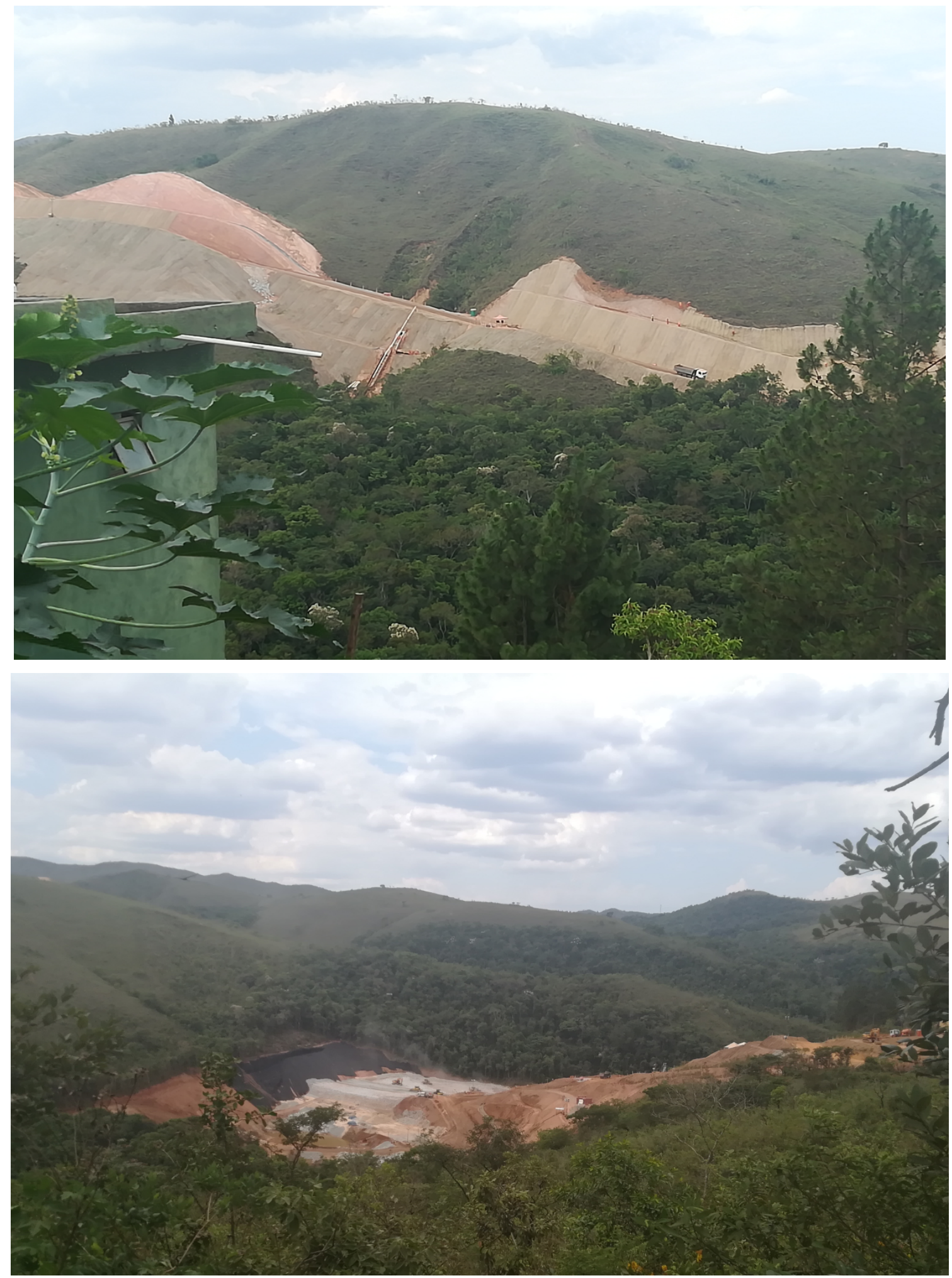

Laschefski, 2019 
Como as barragens B3/B4 são relativamente pequenas, os moradores locais duvidaram da necessidade dessas estruturas gigantescas. Por isso, contrataram um perito independente que confirmou que um dique muito menor nas imediações das duas supostas barragens de risco seria suficiente para evitar uma nova catástrofe (FRANÇA RIBEIRO, 2019). Durante uma conversa em 08 de novembro de 2019, os residentes apresentaram duas hipóteses: A primeira é que duas outras barragens muito maiores associadas ao complexo da mina de Mutuca, que não estão cobertas pela nova lei porque não foram construídas usando o método "a montande", estão em risco de colapso. Ou, assim a segunda hipótese, as obras emergênciais servem na verdade para a abertura de novos projetos imobiliários. Em relação a este último aspecto, convém recordar que, durante os baixos preços do minério de ferro no mercado mundial na primeira década do novo milénio, as mineradoras obtiveram maiores lucros com a construção de zonas residenciais de luxo nas suas propriedades do que com a sua atividade extrativista. Existem mais de 30 desses "condomínios fechados" na região de Macacos (LASCHEFSKI, COSTA, 2008).

Tal como em Barão de Cocais, a vida dos habitantes mudou completamente. Muitos moradores estão com medo as visitas de parentes e amigos diminuiram e o turismo e a gastronomia sofreram uma queda econômica drástica, resultando em demissões (Depoimentos de moradores, 08/11/2019).

Em outras palavras, a empresa está explorando o argumento da emergência para se apropriar sem processo de licenciamento ambiental de extensos terrenos, necessários para a drenagem das barragens de rejeitos e para o depósito de resíduos não recicláveis decorrentes do descomissionamento, ação, ao que tudo indica, planejada antes do crime de Brumadinho. De fato, a estratégia foi usada pela primeira vez em 2016 para construir o Dique 4, que inundou o povoado de Bento Rodrigues, destruído pela ruptura da barragem do Fundão, em Mariana. Com essa medida, os proprietários das terras foram expropriados (G1 Minas, 2016), evidenciando, assim, as novas formas de acumulação por espoliação, viabilizadas pela articulação das empresas criminosas com as instituições do Estado, em torno dos desastres provocados por esse tipo de empreendimento.

\section{Considerações finais}

Os resultados indicam, portanto, que as empresas de mineração estão instalando novas formas de acumulação por despossessão, por meio da articulação com as instituições do Estado. Embora essas tendências já tivessem sido iniciadas antes dos desastres de Mariana e Brumadinho, pudemos observar, depois deles, uma aceleração considerável na flexibilização da legislação e na manipulação de quase todas as instituições sociais e da população. Pelas nossas pequisas, identificamos as seguintes estratégias: 
1. O financiamento das campanhas de candidatos de todos os partidos políticos para os parlamentos federais e estaduais, a fim de criar canais de influência na administração pública e nas instâncias de tomada de decisões, como os conselhos ambientais.

2. Os métodos de objetificação para registros de danos filtram informações, criando categorizações abstratas para reduzir os custos de reparação. Com o mesmo objetivo, as formas tradicionais de uso da terra são criminalizadas pela alegação, entre outras coisas, de ausência de títulos de terra ou de atividades ilegais em áreas protegidas.

3. Um sistema perito de deslegitimação de vários atores é utilizado para fomentar conflitos e um raciocínio competitivo entre as vítimas, mas também entre entidades de assistência técnica e mesmo investigadores universitários.

4. A recuperação dos danos ambientais está seguindo a lógica da natureza itinerante, frequentemente utilizada nos estudos ambientais, segundo a qual os danos ambientais podem ser reparados por medidas de mitigação e compensação. As áreas afetadas pela lama estão sendo replantadas em grande escala, sem consulta aos proprietários das áreas. As áreas "renaturalizadas", anteriormente usadas pelas vítimas, não estão mais disponíveis para uso, o que tem consequências sociais graves, especialmente em áreas comunitárias.

5. O "terrorismo das barragens" tem sido utilizado para aumentar a pressão sobre as autoridades e provocar o medo na população, com o objetivo de realizar grandes projetos de construção relacionados com o descomissionamento de barragens de rejeitos, sem necessidade de licenciamento ambiental.

6. Ao criar territórios de medo nas chamadas zonas de autossalvamento e a consequente queda no preço das propriedades nelas localizadas, as mineradoras criam caminhos para a aquisição das terras necessárias para a sua expansão.

7. O argumento da "vocação mineral" é utilizado para convencer a opinião pública da inevitabilidade do destino de Minas Gerais e do Brasil para o extrativismo mineral, mesmo após os desastres. Dessa forma, a visão dessa suposta dependência mineral, que emergiu na época colonial, está sendo reforçada e cimentada na consciência da sociedade brasileira.

Lançando mão dessas estratégias, as mineradoras penetram nas instituições públicas, nas entidades da sociedade civil e no Ministério Público para manipular a "boa governança" a seu favor. De certa forma, introduziram nesse campo conflituoso uma cultura de troca de favores com atoreschave, uma espécie do neocoronelismo. Nesse jogo, as vítimas dos desastres estão sendo obrigadas a entrar em negociação com os responsáveis pelos crimes, apesar de não serem, na maioria dos casos, politicamente engajadas. Em consequência, a governança do licenciamento ambiental, assim 
como a da gestão dos desastres, nega os direitos das vítimas, ferindo, assim, os princípios da dignidade da pessoa humana do Estado Democrático de Direito, que fundamentam a Constituição Brasileira de 1988. Ao contrário, tal governança atende os interesses das empresas em detrimento das reivindicações legítimas das vítimas, criando inúmeras situações de injustiça ambiental. Ao subordinar o direito à vida e o princípio da precaução aos interesses privados das empresas, as instituições responsáveis pela decisão abandonam definitivamente esse fundamento da Constituição Federal.

Aparentemente, as autoridades ambientais não estão dispostas a alterar o seu comportamento. Em 25 de outubro de 2019, a Samarco obteve permissão para retomar suas atividades em Mariana. Isso, apesar de a questão da reparação das vítimas não ter sido minimamente resolvida e de três barragens em risco de ruptura estarem localizadas em zonas operacionais não abrangidas pelo processo. Ainda mais sério é o fato de que as empresas, por meio de articulação com entes públicos, conseguem também aumentar o controle territorial nas áreas destruídas pelos desastres, utilizando uma estratégia sofisticada de "grilagem oculta" (hidden landgrabbing).

\section{Referências}

ALMG - Assembleia legislativa de Minas Gerais. Futuro da mineração depende de novas práticas. 10/05/2019. Disponível em: $\leq$ https://www.almg.gov.br/acompanhe/noticias/arquivos/2019/05/08_audiencia_setor_minerario.ht $\underline{\mathrm{ml}}>$. Acesso em 19/09/2019.

ARAGAKI, Caroline. Rio Paraopeba está morto e perda de biodiversidade é irreversível. Jornal da USP, 04/04/2019. Disponível em: <https://jornal.usp.br/atualidades/rio-paraopeba-esta-morto-eperda-de-biodiversidade-e-irreversivel/>. Acesso em 19/09/2019.

BRASIL. Constituição da República Federativa do Brasil. Brasília: Senado Federal, 1988.

BEBBINGTON, Anthony. Capitals and capabilities: A framework for analyzing peasant viability, rural livelihoods and poverty. World Development, 27(12), 1999, 2021-2044.

CAMARGOS, Daniel, Meio ambiente ficará melhor que antes da tragédia da Samarco, diz Vale. Folha de São Paulo. 30/01/2018, Disponível em: $<$ https://www1.folha.uol.com.br/mercado/2018/01/1954428-meio-ambiente-ficara-melhor-queantes-da-tragedia-da-samarco-diz-vale.shtml.> Acesso em 19/09/2019. 
CARITAS, 2019. Ocupação chega ao fim de forma vitoriosa. Disponível em: $\leq$ http://mg.caritas.org.br.s174889.gridserver.com/ocupacao-chega-ao-fim-de-forma-vitoriosa/>. Acesso em 19/09/2019.

CMI/COPAM - Câmara de Atividades Minerárias/ Conselho de Política Ambiental. Ata da 37 reunião, realizada em 11 de dezembro de 2018. Disponível em: $\leq$ http://www.reunioes.semad.mg.gov.br/copam_reunioes_01.asp? $\mathrm{x}$ seq_camara $=1 \&$ x_data $=11 / 12 / 2$ 018\&x_seq_reuniao=2037>. Acesso em 19/09/2019.

DE FATO. Documentos apontam interesse da Vale em minerar em áreas evacuadas de Barão de Cocais. 02/05/2019. Disponível em: <https://www.defatoonline.com.br/documentos-apontaminteresse-da-vale-em-minerar-em-areas-evacuadas-de-barao-de-cocais/>. Acesso em 19/09/2019.

DE FATO. Vale já tem 15 barragens suspensas pela justica em Minas Gerais. 17 abr 2019. Disponível em: $\leq$ https://www.defatoonline.com.br/vale-ja-tem-15-barragens-suspensas-pela-justicaem-minas-gerais/>. Acesso em 19/09/2019.

EXAME. Com risco de nova tragédia em MG, Vale se explica ao Congresso. 21 maio 2019. Disponível em: $\leq$ https://exame.abril.com.br/negocios/com-risco-de-nova-tragedia-em-mg-vale-seexplica-ao-congresso/>. Acesso em 19/09/2019.

FIEMG - Federação das Indústrias de Minas Gerais. Descontinuidade Parcial da Atividade de Extração Minerária em Minas Gerais - Impactos Econômicos e Sociais. 2019. Disponível em: $\leq$ https://www7.fiemg.com.br/Cms_Data/Contents/central/Media/Tributos/Impactos_Minerao_Apresenta-o-Sint-tica-vers-o-final-.pdf>. Acesso em 19/09/2019.

FONTES, Letícia. Moradores de Macacos são evacuados por risco de rompimento de barragem. $\mathbf{O}$ Tempo, 16/02/2019. Disponível em: <https://www.otempo.com.br/cidades/moradores-de-macacossao-evacuados-por-risco-de-rompimento-de-barragem-1.2137494> . Acesso em 29/11/2019.

FRANÇA RIBEIRO, Luiz. Recomendações de medidas práticas e eficazes para segurança de barragens. 2019 (mimeo).

G1 MINAS. Justiça dá à Vale direito de ocupar terrenos particulares próximos a Barão de Cocais. 30/05/2019b. Disponível em: $\leq$ https://g1.globo.com/mg/minasgerais/noticia/2019/06/23/talude-de-mina-em-barao-de-cocais-se-movimenta-a-518-cmdia-dizcorpo-de-bombeiros.ghtml>. Acesso em 19/09/2019.

G1 Minas. MP questiona construção de dique em Bento Rodrigues em ação civil pública. 26/09/2019c. Disponível em: $\leq$ http://g1.globo.com/minas-gerais/desastre-ambiental-emmariana/noticia/2016/09/mp-questiona-construcao-de-dique-em-bento-rodrigues-em-acao-civilpublica.html>. Acesso em 19/09/2019.

G1 Minas. Prefeitos de MG temem perda de royalties com decisão da Vale de parar produção em barragens.

Disponível em: $<$ https://g1.globo.com/mg/minas- 
gerais/noticia/2019/01/30/prefeitos-de-mg-temem-perda-de-royalties-com-decisao-da-vale-deparar-producao-em-barragens.ghtml>. Acesso em 19/09/2019.

G1 Minas. Talude de mina em Barão de Cocais se movimenta a $51,8 \mathrm{~cm} / \mathrm{dia}$, diz Corpo de

Bombeiros. 23/06/2019a. Disponível em: $\leq$ https://g1.globo.com $/ \mathrm{mg} / \mathrm{minas}-$ gerais/noticia/2019/06/23/talude-de-mina-em-barao-de-cocais-se-movimenta-a-518-cmdia-dizcorpo-de-bombeiros.ghtml>. Acesso em 19/09/2019.

GIDDENS, Anthony. The Consequences of Modernity. Stanford, Calif: Stanford University Press, 1990.

HARVEY, David. "The 'new' imperialism: accumulation by dispossession." Socialist Register 40, 2004. pp. 63-87.

IFC-International Finance Corporation. Guidance Note 5 Land Acquisition and Involuntary Resettlement. 2012.

INFOMONEY. Vale anuncia que vai fechar 10 barragens semelhantes à de Brumadinho. 29/01/2019. Disponível em: <https:/www.infomoney.com.br/vale/noticia/7897584/vale-anunciaque-vai-fechar-10-barragens-semelhantes-a-de-brumadinho>. Acesso em 19/09/2019.

ITABIRA ONLINE. São Gonçalo - Vândalos alteram sentido de placas de "rotas de fuga". 01/04/2019. Disponivel em: <https://www.itabiraonline.com.br/2019/04/01/sao-goncalovandalismo-nas-placas-instaladas-pela-vale/>, Acesso em 30/12/2019.

ITMNEWS. Vale inicia 2019 com dois novos ativos de minério de ferro. ITMnews, 07/01/2019.

DIsponível em: $\leq$ http://www.inthemine.com.br/site/vale-inicia-2019-com-dois-novos-ativos-deminerio-de-ferro/>. Acesso em 19/09/2019.

LANDER, Edgardo. (org.). Colonialidade do saber. Eurocentrismo e ciências sociais. Colección Sur Sur, Buenos Aires: CLACSO, 2005.

LASCHEFSKI, Klemens. Governança, Neodesenvolvimento e Autoritarismo difuso. In ZHOURI, Andréa, VALENCIO, Norma. (Org.). Formas de matar, de morrer e Resistir. Belo Horizonte: UFMG, 2014. pp. 243-276.

LASCHEFSKI, Klemens; ZHOURI, Andréa. Povos indígenas, comunidades tradicionais e meio ambiente a "questão territorial" e o novo desenvolvimentismo no Brasil. Terra Livre, v. 1, n. 52 (2019),

p. 278-322.

Disponível em: $<$ https://agb.org.br/publicacoes/index.php/terralivre/article/view/1552>. Acesso em 19/09/2019. LASCHEFSKI, Klemens; COSTA, Heloisa Soares de Moura. Segregação social como externalização de conflitos ambientais: a elitização do meio ambiente na APA-Sul, Região Metropolitana de Belo Horizonte. Ambiente e Sociedade (Campinas), v. 11, p. 307-322, 2008.

LEFÈBVRE, Henri. The Production of Space, translated by Donald Nicholson, Oxford: Blackwell. 1991. 
LUXEMBourg, Rosa. The Accumulation of Capital: A Contribution to the Economic Explanation of Imperialism. Berlim: Association Internat. Verl. Anst., 1923.

MANFREDINI, Beatriz. Mesmo com tragédia de Brumadinho, Vale deve lucrar em 2019. IG Brasil Econômico, 18/03/2019. Disponível em: <https://economia.ig.com.br/2019-03-18/valedeve-lucrar-em-2019.html.>. Acesso em 19/09/2019.

MANSUR, Rafaela. Em Barão de Cocais, mais 248 pessoas são retiradas de casa. O Tempo, 10 fev 2019. Disponível em: $\leq$ https://www.otempo.com.br/cidades/desastre-em-brumadinho/em-barão-decocais-mais-248-pessoas-são-retiradas-de-casa-1.2134500>. Acesso em 19/09/2019.

MANUELZÂO. O terrorismo das barragens. Revista Manuelzão 84. 03/2019, p. 22.

MATEUS, Bruno. Mineradoras bancaram 102 deputados eleitos por Minas Gerais em 2014. O Tempo, 31/01/2019. Disponível em: $\leq$ https:/www.otempo.com.br/política/mineradoras-bancaram102-deputados-eleitos-por-minas-gerais-em-2014-1.2129410>. Acesso em 19/09/2019.

MILANEZ, Bruno. ; MAGNO, Lucas ; PINTO, Giffoni Raquel. Da política fraca à política privada: o papel do setor mineral nas mudanças da política ambiental em Minas Gerais, Brasil. Cadernos de Saúde Pública, v. 35, Disponível em: <http://dx.doi.org/10.1590/0102311x00051219>. Acesso em 19/09/2019.

MOORE, Paul. Vale investing US\$390 million in implementation of dry stacking tailings disposal tech from 2020, International Mining, 06/02/2019. Disponível em: $\leq$ https://immining.com/2019/02/06/vale-investing-us390-million-implementation-dry-stacking-tailingsdisposal-tech-2020/>, Acesso em 19/09/2019.

MOTA, Loyslene Freitas; BARCELOS, Tiago Soares. A questão mineral e os índices do IDH-M e GINI nos estados do Pará e Minas Gerais: uma abordagem comparativa. Gestão e Desenvolvimento em Revista V. 4, N. 2, jul-dez/2018, p. 19-35.

MOVSAM - Movimento Pelas Serras E Águas De Minas. SUPPRI e COPAM utilizam estratégias arbitrárias para beneficiar mega-mineradoras que colocam em risco população e meio ambiente. Disponível em: <https://conflitosambientaismg.lcc.ufmg.br/noticias/suppri-ecopam-utilizam-estrategias-arbitrarias-para-beneficiar-mega-mineradoras-que-colocam-em-riscopopulacao-e-meio-ambiente/>. Acesso em 19/09/2019.

MPF/MPE/PF - Ministério Público Federal/ Ministério Público Estadual/ Policia Federal. Recomendação 11/2019. 2019.

OLIVEIRA, Natália. Moradores de Barão de Cocais protestam contra construção de muro pela Vale. O Tempo, 27/04/2019. Disponível em: <https://www.otempo.com.br/cidades/moradores-debarão-de-cocais-protestam-contra-construção-de-muro-pela-vale-1.2174114> Acesso em $19 / 09 / 2019$. 
PALHA, Felipe Pimenta. Campo e rural idílicos como falácia: minério-dependência, incompletude urbana e injustiça ambiental-hídrica em Brumadinho. Tese (Doutorado em Geografia), Universidade Federal de Minas Gerais, 2019.

PARREIRAS, Mateus. Dois anos depois do desastre em Mariana, garimpo e pasto destroem contenções de lama nos rios. Estado de Minas. 14/01/2018. Disponível em: $\leq$ https:/www.em.com.br/app/noticia/gerais/2018/01/14/interna_gerais, 930770/garimpo-e-pastodestroem-contencoes-da-lama-nos-riosdois-anos-depois-d.shtml. . . Acesso em 19/09/2019. PIZZARRO, Ludmila; ARIADNE Queila. Sem pesca, horta e turistas: Rios de Mariana e Brumadinho não dão mais o sustento para famílias; em Macacos, eventos acabaram. O Tempo, 26/06/2019. Disponível em: <https://www.otempo.com.br/economia/sem-pesca-horta-e-turistas1.2199766. Acesso em 19/09/2019.

PODER JUDICIÁRIO DE MINAS GERAIS. Termo de Anuência. Processos n.: 501070936.2019.8.13.0024/5026408-67.2019.8.13.0024/5044954-73.2019.8.13.0024. 21/05/2019.

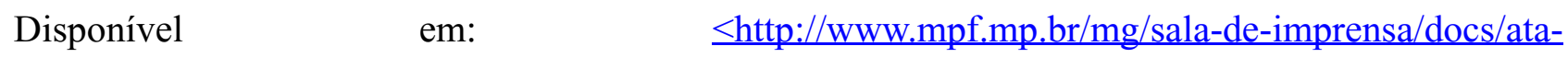
audiencia 6 vara brumadinho $>$. Acesso em 19/09/2019.

PORTO-GONÇALVES, Carlos Walter; ARAUJO QUENTAL de Pedro. Colonialidade do poder e os desafios da integração regional na América Latina, Polis Revista Latinoamericana, 31, 2012. Disponível em: <https://journals.openedition.org/polis/3749>. Acesso em 19/09/2019.

PRATES, Clarissa. Efeitos Derrame da mineração, violencias cotidianas e resistencias em Conceição do Mato Dentro-MG. Dissertação (Mestrado em Sociedade, Meio Ambiente e Território), UFMG-UNIMONTES, Montes Claros, 2017.

REIS, Flavia Maria da Mata. Entre faisqueiras, catas e galerias: explorações do ouro, leis e cotidiano nas Minas do século XVIII (1702-1762). (Mestrado em História), UFMG, Belo Horizonte, 2007.

RENOVA. Dados da Reparação. 2019a. Disponivel em: $\leq$ https://www. fundacaorenova.org/dadosdareparacao/\#acesse>. Acesso em 19/09/2019.

RENOVA, Ofi. NII. 0012019.5145 - Análise do processo de Auto-Identificação realizado por Povos e Comunidades Tradicionais nos territórios Rio Doce e Santa Cruz do Escavaldo (MG). Belo Horizonte 2019b.

ROCHA, Anderson. Tragédia em Brumadinho completa 10 meses com $95 \%$ das vítimas localizadas. Hoje em dia, 25/11/2019. Disponível em: https://www.hojeemdia.com.br/horizontes/trag\%C3\%A9dia-em-brumadinho-completa-10-mesescom-95-das-v\%C3\%ADtimas-localizadas-1.758632. Acesso em 25/11/2019.

RODRIGUES, Leo. MP: Vale tinha ciência que barragem de Brumadinho estava em "atenção". Agencia Brasil, 12/02/2019. Disponível em: <http://agenciabrasil.ebc.com.br/geral/noticia/2019- 

19/09/2019.

SHIVA, Vandana. Monocultures of the Mind. In: SHIVA, Vandana. (Org.) Monocultures of the Mind. London, New Jersey: Zed Books Ltd, 1993, p 9-64.

SOUZA, Clarisse. Membro de CPI na ALMG quer investigação de compra de empresa pela Vale. O Tempo, 04/06/2019. Disponível em: $\leq$ https:/www.otempo.com.br/cidades/membro-de-cpi-naalmg-quer-investigação-de-compra-de-empresa-pela-vale-1.2191755>. Acesso em 19/09/2019.

STAR ONLINE. Vale, miners' shares climb on post-disaster plan to shut dams. Disponível em: $\leq$ https:/www.thestar.com.my/news/world/2019/01/30/vale-says-it-will-sacrifice-output-for-damsafety-in-brazil/>. Acesso em 19/09/2019.

SVAMPA, Maristella. Consenso de los commodities, giro ecoterritorial y pensamiento crítico en América Latina. Revista del Observatorio Social de América Latina, Año XIII N ${ }^{o} 32$ Noviembre de 2012, pp. 15-38. Disponível em: $<$ http://biblioteca.clacso.edu.ar/clacso/osal/20120927103642/OSAL32.pdf $>$. Acesso em 19/09/2019.

TJMG - Tribunal de Justi柠do Estado de Minas Gerais. PJe - Processo Judicial Eletrónico - Número 5026408-67.2019.8.13.0024. 17/10/2019.

TURNER, Barry. Man-Made Disasters. London: Wykeham, 1978.

VALE, João Henrique do. Barreira será construída em Macacos devido a risco de rompimento de barragem. Estado de Minas, 06/07/2019, Disponível em: $\leq$ https://www.em.com.br/app/noticia/gerais/2017/11/02/interna_gerais,913588/concessao-licencapara-barragem-vale-em-itabirito-ignora-advertencia.shtml.>. Acesso em 19/09/2019.

ZHOURI, Andréa; LASCHEFSKI, Klemens. Desenvolvimento e Conflitos Ambientais: Um Novo Campo de Investigação. In: ZHOURI, Andréa; LASCHEFSKI, Klemens. Desenvolvimento e Conflitos ambientais, Belo Horizonte: UFMG, 2010. p. 11-33.

ZHOURI, Andréa; OLIVEIRA, Raquel; ZUCARELLI, Marcos; VASCONCELOS, Max. The Rio Doce Mining Disaster in Brazil: between policies of reparation and the politics of affectation. In: Dossier Mining, Violence, Resistance. Vibrant, v. 14, n.2, 2017.

ZHOURI, A.; VALENCIO, N. ; TEIXEIRA, R. O. S. ; ZUCARELLI, M. C. ; LASCHEFSKI, Klemens ; SANTOS, Ana Flávia Moreira. O desastre da Samarco e a política das afetações: classificações e ações que produzem o sofrimento social. Ciência e cultura, v. 68, p. 36-40, 2016. ZUCARELLI, Marcos. A matemática da gestão e a alma lameada: os conflitos da governança no licenciamento do projeto de mineração Minas-Rio e no desastre da Samarco. Tese (Doutorado em Antropologia), Universidade Federal de Minas Gerais, 2018. 